\title{
Maternal and paternal depression and anxiety and offspring infant negative affectivity: A systematic review and meta-analysis
}

Elizabeth A. Spry ${ }^{1,2}$, Stephanie Aarsman², George J. Youssef ${ }^{1,2}$, George C. Patton ${ }^{2,3}$, Jacqui A. Macdonald ${ }^{1,2,3}$, Ann Sanson ${ }^{3}$, Kimberley Thomson ${ }^{1}$, Delyse M. Hutchinson ${ }^{1,2,3,4}$, Primrose Letcher*1,2, Craig A Olsson*1,2

* Denotes equal contribution

1. Deakin University Geelong, Centre for Social and Early Emotional Development, School of Psychology, Faculty of Health; Geelong, AUSTRALIA

2. Murdoch Children's Research Institute, Centre for Adolescent Health; Melbourne, AUSTRALIA

3. University of Melbourne, Department of Paediatrics, Royal Children's Hospital, Australia

4. University of New South Wales, National Drug and Alcohol Research Centre, Faculty of Medicine, Australia

Corresponding author: Elizabeth Spry (elizabeth.spry@mcri.edu.au)

Postal address:

The Centre for Adolescent Health

Murdoch Children's Research Institute

The Royal Children's Hospital

50 Flemington Road,

Parkville 3052, Victoria, Australia 


\begin{abstract}
Maternal internalizing symptoms during pregnancy, specifically depression and/or anxiety, are commonly linked to negative affectivity (NA) in infant offspring. These links are commonly attributed to biological effects of the in utero environment on fetal development. However, research suggests that internalizing symptoms before and after pregnancy, as well as in fathers, may also be associated with NA in infant offspring. Such findings suggest greater complexity in transmission than can be explained by biological in utero programming alone. Further, infant NA is often treated as an homogenous construct, yet it covers a range of facets including fear, frustration, sadness, and slow recovery from distress that may each be differentially associated with parent internalizing distress. Here we aimed to (1) meta-analytically quantify associations between maternal and paternal internalizing symptoms and infant offspring NA, (2) examine how associations varied as a function of distinct phenotypic facets of NA, and (3) examine how associations varied by timing of parental symptoms (preconception, antenatal, postnatal) and infant age. Using random-effects meta-analysis, we found that maternal internalizing symptoms were positively associated with infant NA $(r=0.17$ [95\% Cl 0.14, 0.21], 42 studies, 149 estimates). Preliminary evidence from studies of fathers likewise suggested a positive association with infant NA ( $r=0.13$ [95\% Cl 0.04, 0.22], 6 studies, 40 estimates). We observed associations with the global infant NA construct, as well as effect modification by infant NA facet (maternal $r$ range .12 to .22 ; paternal $r$ range .03 to.21). In mothers, there was no evidence of effect modification by timing of internalizing symptoms or infant age; in fathers, preliminary associations were larger for postnatal than antenatal symptoms. Further studies of preconception and paternal symptoms are now needed, and we suggest avenues for research to advance understanding of the relations between parent internalizing symptoms and infant NA.
\end{abstract}

Key words: Perinatal depression; preconception; father; mother; negative affect; infant development; intergenerational; emotional reactivity 


\section{Highlights}

- In mothers, both antenatal and postnatal internalizing symptoms predict infant negative affectivity.

- In fathers, postnatal internalizing symptoms predict infant negative affectivity.

- Findings are consistent with both in utero biological programming and postpartum interpersonal stress transmission models.

- The strength of associations between parent symptoms and infant negative affectivity varies by type of infant negative affectivity assessed.

- Further research on potential preconception, paternal and confounding influences is needed. 


\section{Introduction}

Children differ in the way they react to the environment. These differences, evident from infancy, interact with experience to shape lifelong patterns of mental health and disorder. One of the earliest emerging dispositional traits is negative affectivity (NA), a bias to negative mood that is characterized by individual differences in tendency to emotional distress (Rothbart \& Bates, 2006). NA is conceptually related to the personality trait of neuroticism, as well as the more recently proposed $p$-factor, a transdiagnostic risk factor for psychopathology (Hankin et al., 2016). Across the life-course, dispositional NA is a key risk factor for depression and anxiety disorders, as well as greater comorbidity and poorer prognosis (Cuijpers et al., 2010; Kotov et al., 2010; Lahey, 2009; Letcher et al., 2009). Understanding the development of NA has therefore been an important transdisciplinary research goal.

Rothbart's psychobiological model of temperament has emerged as a dominant theoretical foundation for research investigating the development of NA, integrating neuroscientific, developmental and comparative lines of inquiry (Gartstein, 2019). According to this model, individual differences in NA develop as a function of biological, maturational and contextual influences (Goldsmith et al., 1987; Rothbart \& Derryberry, 1981). There is increasing evidence that NA is evident as early as the first days of life, and underpinned by differences in brain regions implicated in the stress response system (Gunnar \& Davis, 2013; Shackman et al., 2016). Stability estimates of NA are typically low to moderate in early infancy, increasing across the first year postpartum (Bornstein et al., 2015; Carranza Carnicero et al., 2000). This consolidation of trait-like NA over time is thought to be influenced by maturation and contextual input; in infancy, contextual inputs are mostly parent-mediated (Putnam et al., 2002; Rothbart, 2004).

The most studied predictors of infant NA are maternal internalizing symptoms (depression and/or anxiety). Depression and anxiety affect up to $24 \%$ of women during pregnancy and the first year postpartum (Woody et al., 2017), and reliably predict increased risk for mental health difficulties in offspring that extend into adulthood (Madigan et al., 2018; O'Connor et al., 2014; Sanger et al., 2015; Stein et al., 2014). Understanding the early emergence of these intergenerational links may elucidate transmission pathways and aid in early identification of children at risk. Because NA is one of the earliest observable dimensions of socio-emotional development in infants, associations between maternal internalizing symptoms and infant NA have thus received considerable attention (Davis et al., 2004; Gustafsson et al., 2018; Henrichs et al., 2009; Nolvi et al., 2016). 
Although the literature has focused primarily on maternal associations, there is increasing interest in the role of fathers (Connell \& Goodman, 2002). Perinatal depression affects up to $13 \%$ of fathers (Cameron et al., 2016; Paulson \& Bazemore, 2010), and has been linked to increased risk of emotional and behavior difficulties in offspring (Gutierrez-Galve et al., 2015; Sweeney \& MacBeth, 2016). These associations may occur both via and independently of maternal symptoms (Goodman, 2020), with increasing involvement of fathers in caregiving potentially leading to greater influences on children's emotional development (Natsuaki et al., 2014; Ramchandani \& Psychogiou, 2009). Paternal internalizing symptoms during pregnancy and postpartum are also implicated in the early emergence of offspring NA and related behaviors during infancy (Ting, 2012; van den Berg et al., 2009).

\section{Is there early specificity in intergenerational patterning of infant NA?}

Though often described as a unitary construct that reflects general distress-proneness, NA also comprises several narrower, interrelated, dimensions. The number and definition of these facets varies somewhat across developmental stage of the life-course, but most models include sadness, anxiety/fear, and anger/frustration (Hankin et al., 2016). In infancy, NA is thought to encompass distinct facets of sadness, fear, frustration/irritability, and falling reactivity or rate of recovery from distress (Table 1). Typically, these emotional states are inferred by caregivers or other observers on the basis of infant behavioral patterns in response to specific contextual cues, commonly associated with each emotional state (Planalp \& Goldsmith, 2019). While the extent to which observers can accurately infer infant emotional experience is unclear (Barrett et al., 2019), there is some evidence that these behavioral patterns differ in expected ways in their situational triggers, neurobiological correlates and mental health outcomes, and therefore may act as discrete behavioral markers of risk (Clauss \& Blackford, 2012; Kagan et al., 1999, 2007; Planalp \& Goldsmith, 2019; E. Thomas et al., 2019). It is unclear whether associations between parent internalizing symptoms and infant NA reflect an intergenerational patterning of broad distress-proneness, as reflected by the general NA construct, or whether associations vary by facet of infant NA.

Insert Table 1 here

Studies examining the potential role of infant NA in intergenerational transmission of internalizing symptoms focus on two overarching symptom categories: depression and anxiety. Though 
comorbid, depression and anxiety are partially discrete disorders with distinct predictors, onset and course trajectories, and functional outcomes (Kessler et al., 2015; Korja et al., 2018; Penninx et al., 2011). Perinatal depression and anxiety differ in their biological correlates and links to broad offspring socio-emotional development (Field, 2011; Madigan et al., 2018), and may similarly differ in their associations with infant NA. One mechanism may be the way in which depressive and anxious symptomatology differentially impact parent-infant interactions, with evidence of dyadic gaze and touch synchrony differing between depressed and anxious mothers and their infants (Granat et al., 2017).

Parental depression and anxiety may also relate differently to the various facets of infant NA. Latent structural models of psychopathology suggest that fear and sadness are dimensions of internalizing distress, associated with anxiety and depression respectively (Hankin et al., 2016), while frustration/irritability are more closely aligned with externalizing difficulties (Muris \& Ollendick, 2005; Stanton \& Watson, 2014). More broadly, prior work on intergenerational transmission suggests homotypic continuity from parent to child is stronger than heterotypic continuity (Warner \& Weissman, 2013). It is not known whether this pattern of intergenerational homotypic continuity is evident from early infancy of offspring but if so, we may expect to see stronger associations of parental anxiety with infant behavioral patterns commonly attributed to fear, and parental depression with infant behavioral patterns commonly attributed to sadness, and weaker associations of both parent depression and anxiety with infant behavioral patterns commonly attributed to frustration/irritability (Hankin et al., 2016; Stanton \& Watson, 2014).

\section{Does timing of parent internalizing symptoms or infant NA matter?}

The timing of children's exposure to parent internalizing symptoms may implicate different mechanisms of risk transmission (Goodman, 2020). Theoretical explanations tend to emphasize potential influences of parental symptoms during a critical or sensitive developmental window of offspring development, and vary in the extent to which they emphasize processes before or after birth. It is worth noting that these perspectives are not mutually exclusive or incompatible. Overwhelmingly, the current narrative in the literature on predictors of infant NA is dominated by the fetal programming hypothesis, which posits that maternal antenatal symptoms affect infant neurodevelopment, affect and behavior via in-utero exposure to stress hormones, immuneinflammatory processes, or microbiota (Chan et al., 2017; Glover, 2011; Van den Bergh et al., 2017). Accordingly, most prospective studies of parental internalizing symptoms and infant NA focus on 
maternal exposure during pregnancy (Davis et al., 2004; Gustafsson et al., 2018; Henrichs et al., 2009; Nolvi et al., 2016; Rouse \& Goodman, 2014).

However, biopsychosocial models of infant NA also suggest a role of postnatal processes (Rothbart \& Bates, 2006). According to interpersonal stress transmission models, postnatal internalizing symptoms may impact infants' emotional development via parent-infant interactions and the broader relational environment (Hammen et al., 2004; Meaney \& Szyf, 2005). Much postnatal evidence is cross-sectional (Beck, 1996; Pickens \& Field, 1993), reflecting potential bidirectional effects or common causes (Yim et al., 2015). Nonetheless, there is also prospective evidence for both mothers and fathers (Jonas et al., 2015; Potapova et al., 2014). Further, emerging findings also link maternal stress-related exposures before pregnancy to infant behavior and affect (Hipwell et al., 2019; Petzoldt et al., 2015; Spry et al., 2019). Evidence from animal studies suggests preconception programming of the germline or reproductive biology by both maternal and paternal preconception stress, impacting the future gestational environment and fetal development (Keenan et al., 2018; Klengel et al., 2015). Alternative explanations include confounding by common causes, or mediation by perinatal processes.

Comparing the size of maternal and paternal associations within and across phases has become one widely used strategy for drawing inferences from observational data (Thapar \& Rice, 2020; Thapar \& Rutter, 2019). While this strategy cannot directly test mechanisms, it can provide some evidence in support of, or against, theoretical perspectives and inform future mechanistic research. In particular, antenatal paternal exposures are often employed as a 'negative control' when evaluating evidence for the fetal programming hypothesis (Gage et al., 2016). Under this model, antenatal associations should be much smaller for paternal than maternal symptoms, given the absence of a direct in-utero programming pathway. Thus, similar sized maternal and paternal antenatal associations may suggest confounding. In contrast, maternal and paternal associations are both plausible postnatally and before conception, under the interpersonal stress transmission and preconception programming models. Differences in magnitude of associations over time may provide a further line of evidence. For example, evidence of postnatal, but not antenatal associations may support an interpersonal stress transmission model. Conversely, similar sized associations at each phase may suggest either multiple processes operating over time, or confounding either by earlier/later symptoms or common causes. While not definitive, these lines of evidence have the potential to advance thinking in the area. 
Infant age at the time of NA assessment may similarly moderate associations. As already described, individual differences in NA are evident from early infancy with stability increasing across the first year postpartum. This suggests a potential role of parental factors both before and after birth. According to fetal/preconception programming hypotheses, associations between parent internalizing symptoms and infant NA may be apparent from the early postpartum. An interpersonal stress transmission model may suggest that associations increase across infancy, with exposure to postpartum symptoms (Newland et al., 2016). Additionally, while individual differences in undifferentiated distress-proneness are discernible from early infancy, more nuanced dimensions may begin to cohere across infancy. Distinct behavioral patterns commonly attributed to sadness, fear, and frustration to limitations are discernible by 3 months postpartum, with frustration and fear reactions increasing across the first year of life (Gartstein \& Hancock, 2019; Gartstein \& Rothbart, 2003; Stenberg \& Campos, 1990). Associations of parental internalizing symptoms with each facet may thus differ across this maturational timeline.

\section{Methodological considerations}

The magnitude of associations between parental internalizing symptoms and infant NA may also be influenced by measurement approaches. While some studies have employed diagnostic assessments of parent symptoms to identify probable disorder, others have used screening checklists. Similarly, there is debate surrounding the assessment of infant NA via maternal report, as compared to observational assessment (Luoma et al., 2004; Najman et al., 2001). In most studies of parentreported infant NA, the same parent reports on both on their own internalizing symptoms and on their infant's NA. This introduces potential biases, including inflated effect sizes due to shared method variance (Richters, 1992). However, observational assessments are typically conducted under artificial conditions that limit their ecological validity (Bates et al., 2014; Shiner \& Caspi, 2003). Because each measurement mode assesses slightly different constructs and may be susceptible to different forms of bias, it is important to compare studies using parent report with those using observational ratings.

\section{The current systematic review and meta-analyses}

Because infant NA is associated with parent depression and anxiety and is, in turn, one of the earliest infant predictors of emotional or behavioral difficulties, this early life disposition has been implicated in the intergenerational transmission of risk for depression and anxiety (Bruder-Costello 
et al., 2007; Rothbart et al., 2000). In this context, understanding links between parental internalizing symptoms and infant NA may inform early interventions for children at greater risk, and ultimately reduce enduring negative impacts on the mental health of the next generation. However, gaps in our understanding remain. First, although many studies have examined prospective associations between parent internalizing symptoms and infant NA, these have not been quantitatively synthesized. Past reviews confound multiple infant dispositional traits with distinct etiological pathways and links to parental symptoms, or identify associations broadly across childhood / adolescence rather than specifically in infancy (Beck, 1996; Erickson et al., 2017; Goodman et al., 2011). Further, prior empirical studies vary considerably in the nature and timing of measurement of infant NA and parental symptoms. Examining this variability would allow us to address key conceptual questions relating to the complex nature of infant NA, and the implications of assessment timing for dominant theoretical models of transmission.

The purpose of this systematic review and meta-analyses was thus threefold. First, we sought to meta-analytically quantify the prospective associations between parent internalizing symptoms and offspring NA in infancy, for mothers and fathers. Second, we sought to examine whether there is early specificity in the intergenerational patterning of infant NA, as reflected by effect modification by parent internalizing construct and/or infant NA facet assessed. Third, we sought to examine whether associations vary by timing of parental symptoms (postnatal, antenatal or preconception) and infant age. Addressing these questions can inform our understanding of the associations between maternal and paternal internalizing symptoms and the early emergence of NA in offspring, with lifelong implications for mental health and ill health. 


\section{Methods}

\section{Research design and methods}

This systematic review and meta-analysis was carried out according to the preferred reporting items for systematic review and meta-analysis guidelines (Moher et al., 2009), and in adherence to a predefined study protocol registered on PROSPERO (CRD42019118033).

\section{Search strategy}

We searched Medline, PsycINFO, CINAHL, PubMed, OpenGrey and OpenDissertations to identify published and unpublished literature (initial search conducted 4/12/2018; search update conducted $11 / 4 / 2020$ ). Our search was based on five broad criteria, each of which was translated into a set of key words for searching in title and abstract. These categories are: (S1) reactivity (key words $A B$ "negative affect" OR AB "negative affectivity" OR AB "negative react*" OR temperament OR "emotion* react*" OR "react* NO behavi*" OR colic OR fussy OR crying OR "behavi* NO difficult*" OR "emotion* difficult*" OR "stress sensitiv*" OR "stress react*" OR "temperamental negativity" OR "stress respons*" OR "emotional problems" OR "behavi*ral problems" AB sadness OR fear OR "frustration tolerance" OR irritability OR mood OR "falling reactivity" OR "distress to limitations" OR "recovery from distress"); (S2) infancy (key words infan* OR toddler* OR newborn OR baby* OR neonat* OR offspring OR preschool OR child); (S3) parent (key words maternal OR mother OR parent* OR paternal OR father); (S4) preconception, pregnancy or postpartum (key words prepregnancy OR "pre-pregnancy" OR lifetime OR preconception OR "pre-conception" OR perinatal OR postnatal OR postpartum OR antenatal OR antepartum OR pregnancy OR pregnant OR gestation OR periconception* OR “in-utero" OR trimester OR peripartum); and (S5) mental health (key words internalizing OR internalizing OR externalizing OR externalizing OR "mental disorder" OR "mental health" OR "depress*" OR "anxi*" OR "mood disorder OR "affective disorder" OR "anxiety disorder" OR “PTSD” OR MDD OR "posttraumatic stress" OR psychopathology).

These criteria were combined as follows: (a) studies with at least one key word within both (S1) and (S2) to obtain studies that included NA during infancy (S6); (b) studies with at least one key word within (S3), (S4) and (S5) to obtain studies that included parent internalizing symptoms prior to, during, and/or after pregnancy (S7); and (c) studies with at least one key word within each of (S6) and (S7) to obtain studies that included both infant NA and parent internalizing symptoms. Reference lists of relevant papers were also searched. 


\section{Eligibility}

Inclusion criteria. Studies were included if: (a) the study included NA as an outcome, assessed via parent rating or observer report; (b) mean age of children at the time of the outcome assessment was 18 months or younger; (c) the study included a measure of maternal and/or paternal internalizing symptoms before pregnancy, during pregnancy, or in the first year postpartum, assessed using a diagnostic interview or validated rating scale; (d) the study used a prospective longitudinal design to assess antenatal or postnatal internalizing symptoms, with parental symptoms assessed prior to offspring outcome; for preconception symptoms only, we also included retrospective assessment because we expected few studies with prospectively assessed preconception symptoms in the literature; (e) sufficient information to calculate an effect size was presented; and (f) the study was written in English.

Exclusion criteria. Physiological, biochemical, immuno-inflammatory or other biological measures of NA were excluded, as well as the conceptually distinct constructs of difficult temperament, which encompasses a range of temperamental traits, and behavioral inhibition/avoidance and its components .

\section{Data extraction and study quality}

Data from each included study were coded using a pre-piloted data extraction form, including: study characteristics (country, number of participants); study design; gender of parent; exposure measure, assessment method, and timing; sex of infant; outcome measure, assessment method, and timing; and estimates of association. All studies and key variables were coded by primary coder (SA), and verified by a second coder (ES). Results were compared and disagreements resolved by consensus coding. Inter-rater reliability was Cohen's $k=0.88-1.00$ for the categorical coding of studies and variables, and Pearson's $r=.99$ for effect sizes. Study quality was assessed using a 13-point quality assessment tool adapted from the National Institutes of Health Quality Assessment Tool for Observational Cohort and Cross-Sectional Studies (Madigan et al., 2018; National Heart Lung and Blood Institute: National Institutes of Health, 2014). This tool is designed to evaluate study design elements according to Cochrane collaboration criteria (Downes et al., 2016)and adapted for relevance to intergenerational cohorts (Supplementary Table 1).

\section{Statistical analysis}

For mothers and fathers separately, we first used meta-analytic methods to provide a general quantitative synthesis of the literature. Associations between maternal and paternal internalizing 
symptoms and infant NA were examined using univariate random effects models, based on the assumption of between-study heterogeneity. Most studies reported multiple effect sizes (e.g., associations of antenatal v. postnatal symptoms, or associations of parental anxiety v. depression). Estimates were therefore nested within studies. We used robust variance estimation with small sample adjustment to account for dependent effect sizes (Hedges et al., 2010; Tipton, 2015). This allowed us to include all estimates of association from each study and avoids the limitations of within-study effect averaging or elimination, such as loss of information or the assumption of homogeneous effect sizes within studies (Assink, 2016).

Heterogeneity was evaluated using prediction intervals, which estimate the range of true effect sizes within which $95 \%$ of all populations would fall. In the absence of between study heterogeneity of true effect sizes, the prediction interval mirrors the confidence intervals around the weighted average effect size. If heterogeneity is present, the prediction interval covers a wider range than the confidence interval (Borenstein et al., 2017; IntHout et al., 2016). The $I^{2}$ statistic was also evaluated, indicating the proportion of observed variance not attributable to sampling error (Borenstein et al., 2017). To examine the extent to which heterogeneity could be explained by the proposed moderators, analyses were repeated first adjusted for each moderator, and then stratified by each moderator. Where the number of studies was too low for meta-analyses $(k<2)$, data were qualitatively evaluated (Valentine et al., 2010). Where the number of studies was low but sufficient for meta-analysis $(k \geq 2)$, data were nonetheless meta-analyzed and results presented to indicate current levels of evidence. Meta-analytic estimates with low k and high variance / low precision as indicated by wide confidence intervals, reflecting wide variation in effect sizes across studies, were not considered substantively meaningful.

The most common metric for reporting effect sizes within included studies was the Pearson correlation coefficient $(r)$. Other effect sizes were therefore converted to $r$, using effect size transformation formulae (Borenstein et al., 2011). Because few studies adjusted for potential confounding variables at or before baseline, we meta-analyzed unadjusted estimates. All estimates of association were transformed to Fisher's z-scores for analysis and then back-transformed to aid interpretability. All random effect analyses were conducted in R (R Core Team, 2018). Meta-analyses were conducted using 'robumeta' (Fisher et al., 2017). P-values for moderation analyses were derived using Wald tests with (unless otherwise specified) the default Hotelling's $\mathrm{T}_{Z}^{2}$ small sample correction, implemented in 'clubsandwich' (Pustejovsky, 2020; Tipton \& Pustejovsky, 2015).

\section{Publication bias}


Potential publication bias was examined using five methods, separately for mothers and fathers: the Fail-Safe N, the Egger test, visual inspection of funnel plots, rank correlation test for funnel plot asymmetry, and a stratified analysis by publication status (published versus unpublished studies).

Data and analysis scripts are available at

https://osf.io/nmqdb/?view_only=0a36df8ddd4644d1b4f9d25a0daa8e49

\section{Moderators}

Dimension of infant NA was defined according to Rothbart's model (negative affectivity and its four facets: sadness, fear, frustration/irritability, and slow recovery from distress; Gartstein \& Rothbart, 2003). We present coding decisions for questionnaire and observational measures in Table 1. For observational measures where both the observational and rating protocol were designed to elicit a range of negative emotions (e.g., the Harvard Infant Behavioral Reactivity Protocol), we coded as general NA; where either the observational or rating protocol was designed to elicit a specific facet of NA (e.g., arm restraint protocol to elicit frustration/irritability) we coded as that facet.

Parent internalizing construct was coded as a binary variable: anxiety or depression, indicating the presence of anxiety or depressive disorder/symptoms as indicated by diagnostic interview or screening measure.

Infant age at NA assessment was coded as a binary variable: $<$ or $\geq 6$ months postpartum.

Timing of parent internalizing symptoms was coded as a three-level categorical variable: preconception, antenatal, or postnatal. Within the antenatal category we derived an additional variable denoting: first, second, or third trimester. Within the postnatal category we derived an additional variable denoting: $<$ or $\geq 6$ months postpartum.

Infant NA assessment mode was coded as a binary variable: observer-rated or parent-reported.

Parent internalizing symptoms assessment mode was coded as a binary variable: diagnostic interview or self-report via symptom checklist. 


\section{Results}

Figure 1 provides a PRISMA flow diagram (Moher et al., 2009) of the article selection process. We identified 601 articles via the database search, and a further 26 articles by manually searching reference lists of key articles. Of these, 547 articles remained after duplicates were removed. Review of the titles and abstracts yielded 156 articles identified as potentially meeting full inclusion criteria. After reviewing the full text of these articles, 45 were identified as meeting full inclusion criteria.

Insert Figure 1 here

\section{Study characteristics and quality}

Study characteristics are shown in Table 2. In total, 45 articles with 233 effect sizes were identified through the systematic search. Sample sizes within studies ranged from 22 to 5568 parent-infant dyads. A total of 20 studies were from North America, 18 studies from Europe, five from Asia, and three from Australia/New Zealand. Of the 45 included studies, 41 were peer reviewed journal articles and six were unpublished doctoral theses. Forty-two studies included estimates for maternal internalizing symptoms, and six studies included estimates for paternal internalizing symptoms (three of these studies included estimates for both maternal and paternal symptoms. Mean study quality score was $6.0(S D=1.5$, range 2-9) (Supplementary Table 2). Although inclusion criteria permitted retrospectively assessed preconception symptoms, the search only yielded studies of prospectively assessed symptoms.

Insert Table 2 here

\section{Maternal internalizing symptoms}

Table 3 shows the meta-analytic estimates of associations between mothers' internalizing symptoms and infant NA, as well as the meta-regression and moderator results. A total of 149 effect sizes from 42 studies, including 19,248 mother-infant dyads, were available to estimate the associations between maternal internalizing symptoms and the global construct of infant NA, with correlation coefficients ranging from $r=-.21$ to $r=.56$. The weighted average effect size from the random effects model was $r=0.17(95 \% \mathrm{Cl} .14, .21)$. The variance in effect sizes attributable to true differences between studies was estimated as $\mathrm{I}^{2}=81 \%$ of total observed variance, suggesting that effect sizes were more heterogeneous than expected by sampling error alone. The prediction 
interval $(I=-.02$ to .37$)$ was wider than the confidence interval around the weighted average effect size, also indicating some heterogeneity of true effect sizes between populations.

Insert Table 3 here.

\section{Moderator analyses}

Infant NA dimension assessed. Maternal internalizing symptoms were associated with all facets of infant NA as well as the general construct, but there was nonetheless meta-analytic evidence of difference in effect size by outcome construct assessed $(p=.044)$. Effect sizes were highest for the general construct of NA $(r=.21[.17, .26], k=26)$ and sadness ( $r=.22[.06, .37], k=8)$, and smaller for fear $(r=.12[.07, .16], k=15)$, frustration/irritability $(r=.14[.08, .20], k=18)$, and slow recovery from distress ( $r=.14[03, .24], k=8)$. In supplementary analyses (Supplementary Table 3), we further examined whether associations between maternal symptoms and each dimension of infant NA varied by type of maternal mental health problem. For infant fear, effect sizes were larger for maternal anxiety $(r=.18[.07, .29], k=6)$ than maternal depression $(r=.08[.03, .13], k=11)$. There was no other evidence that associations between maternal symptoms and each NA dimension varied by type of mental health problem.

Maternal internalizing construct assessed. There was no other meta-analytic evidence of difference in effect size according to the exposure construct measured (anxiety $r=.19[.15, .23], k=19$; depression $r=.17[.12, .21], k=29 ; p$ for test of moderation $=.571$; Table 3 ).

Infant age at NA assessment. There was no meta-analytic evidence of difference between assessments conducted during or after the first six months postpartum $(<6$ months $r=.16[.11, .21]$, $k=22) ; \geq 6$ months $r=0.17$ [.12,.22], $k=24$; $p$ for test of moderation $=0.865$ ). In supplementary analyses (Supplementary Table 3), we further examined whether associations between maternal internalizing symptoms and each dimension of infant NA varied by timing of infant NA assessment. For infant slow recovery from distress, effect sizes were larger for studies where maternal symptoms were assessed after six months postpartum $(r=.17[.03, .30], k=5)$ than before six months postpartum $(r=.07[-0.29, .42], k=3)$, though the test of moderation was not significant $(p=.314)$. There was no other evidence that associations between maternal symptoms and each NA dimension varied by timing of infant NA assessment.

Timing of maternal internalizing symptom assessment. There was no meta-analytic evidence of difference between antenatal and postnatal effect sizes (antenatal $r=.18[.13, .22], k=33$; postnatal $r=.17[.10, .23], k=12 ; p$ for test of moderation $=0.081$ ). Similarly, there was no evidence of 
difference between pregnancy trimesters or between assessments conducted during or after the first six months post-partum. Only one study examined maternal preconception symptoms, although this study replicated findings across two independent samples (adolescent-only $r=.11$; young adultonly $r=.15$; adolescent and young adult $r=.38$ ) (Spry et al., 2019).

Assessment mode. For all studies of maternal internalizing symptoms and parent-reported infant NA, mothers reported on both their own symptoms and their infant's NA. There was no evidence that effect sizes varied by mode of maternal symptom assessment (clinical interview $r=.19[.09, .30], k=$ 6 ; self-report via symptom checklist $r=.18[.14, .22], k=38$; $p$ for test of moderation $=.628$; Table 3 ), or mode of infant negativity assessment (parent report $r=.18[.15, .22], k=38$; observational assessment $r=.16[-.08, .38], k=6$, test of moderation $p=.674)$.

\section{Paternal internalizing symptoms}

Table 4 shows the meta-analytic estimates of associations between fathers' internalizing symptoms and infant NA, as well as the meta-regression and moderator results. A total of 40 effect sizes from 6 studies, including 1,235 father-infant dyads, were available to estimate the associations between paternal symptoms and the global construct of infant NA. The weighted average effect size from the random effects model was $r=0.13(95 \% \mathrm{Cl} .04, .22)$. The variance in effect sizes attributable to true differences between studies was estimated as $\mathrm{I}^{2}=70 \%$ of total observed variance, suggesting more heterogeneity than would be expected by sampling error alone. The prediction interval $(r=-.17$ to $.40)$ was wider than the confidence interval around the weighted average effect size, indicating some heterogeneity of true effect sizes between populations.

Insert Table 4 here.

\section{Moderator analyses}

Infant NA dimension assessed. Effect sizes were larger for general NA $(r=.20[-.19, .53], k=2)$, sadness $(r=.20[.18, .22], k=2)$, and slow recovery from distress $(r=.21[.08, .35]), k=2$, smaller for frustration/irritability $(r=.13[-.11, .35], k=3)$, and negligible for fear $(r=.03[-.05, .11], k=3), p$ for test of moderation $=.003$.

Paternal internalizing construct assessed. There was no meta-analytic evidence of difference in effect size according to the exposure construct measured (anxiety $r=.10[-.05, .10], k=4$; depression $r=.12[.01, .23], k=4 ; p$ for test of moderation $=.329)$. 
Timing of infant NA assessment. The weighted average effect size was slightly higher in studies with infant NA assessments at $\geq 6$ months $(r=.15[.01, .29], k=4)$ than $<6$ months $(r=.09[-.04, .21], k=$ $3)$, though the test of moderation was not significant $(p=.138)$.

Timing of paternal internalizing symptom assessment. There was meta-analytic evidence that associations between paternal symptoms and infant NA were larger in studies where paternal symptoms were assessed postnatally $(r=.19[.09, .28], k=3)$ than antenatally $(r=.07[.04, .19], k=$ $3), p$ for test of moderation $=.022$. No studies examined paternal preconception symptoms.

Assessment mode. For all studies of paternal internalizing symptoms and parent-reported infant NA, fathers reported on their own symptoms and their infant's NA. We were unable to examine effect modification by exposure or outcome assessment mode, because only one study used diagnostic assessment of fathers, and no studies used observational rating of infant NA.

\section{Small sample and publication bias}

The Fail-Safe $\mathrm{N}$ indicated that 6386 studies for mothers, and 52 studies for fathers, with null results would be needed to negate the significance of our sample of studies. The Rosenthal approach was used for all Fail-Safe $\mathrm{N}$ tests with the target significance level $p=.05$ (CRAN; Rosenthal, 1979). The Egger test was significant for mothers $(z=2.21, p=.027)$, and non-significant for fathers $(z=.84, p=$ $.400)$. Funnel plots were examined for indication of bias. When no bias is present, the plot resembles an inverted funnel with effect sizes dispersed symmetrically around the mean effect size. Studies with large samples and small standard error are located closer to the top of the funnel, while studies with smaller effect sizes and larger standard error are closer to the bottom (Borenstein et al., 2011). The funnel plots suggested some asymmetry, though the rank correlation test for funnel plot asymmetry indicated a non-significant relationship between sample size and effect size for mothers (Kendall's Tau $B=.05, p=.636$ ) and fathers (Kendall's Tau $B=.20, p=.719$ ). The stratified analysis yielded similar effect sizes for published and unpublished literature for mothers (unpublished $r=.22$, $\mathrm{k}=4$; published $r=.17 ; \mathrm{k}=38$ ) and fathers (unpublished $r=.12, \mathrm{k}=3$; published $r=.15, k=3$ ). 


\section{Discussion}

We conducted a comprehensive systematic review and meta-analysis of the associations between maternal and paternal internalizing symptoms and infant NA, and examined the impact of potential moderators. Overall, the evidence suggests a modest association between parental symptoms and infant NA, for both mothers and fathers. These associations were similar in size to those of a prior meta-analysis of maternal depression and offspring NA across childhood and adolescence (Goodman et al., 2011). Our findings suggest that these associations are already evident, to a similar degree, in infancy. In addition to increased general distress-proneness in infants of parents with internalizing symptoms, we also found some specificity in associations with the distinct facets of infant NA. In mothers, there was no evidence that associations varied by exposure or outcome timing. In fathers, preliminary findings suggest that associations were larger when paternal symptoms were measured postnatally.

\section{Is there specificity in associations between parent internalizing symptoms and infant NA?}

We investigated potential intergenerational homotypic continuity of parent internalizing distress and related dimensions of infant NA (Hankin et al., 2016). Overall, in mothers, associations were largest for the overall dimension of infant NA, and the sadness facet. Associations were smaller (around two thirds of the size) for fear, frustration/irritability and slow recovery from distress. While few studies have examined paternal associations with each facet, the overall pattern of paternal findings was mostly similar to that observed for mothers. Taken together, these findings provide support for parental patterning of general distress-proneness in infants.

As expected, infant fear was associated with higher maternal anxiety, but not maternal depressive symptoms. Prior research has found homotypic continuity of parent/observer-rated fear from infancy to childhood (Putnam et al., 2008), and associations between early life fear and anxiety symptoms in childhood and adolescence (Kagan et al., 1999, 2007). Our findings build on this research by further suggesting that infant behavioral patterns commonly attributed to fear may be an early marker of intergenerational homotypic continuity of fear-based anxious distress. In contrast, we found no evidence of specificity in relation to infant sadness. Behavioral patterns typically attributed to sadness may reflect a non-specific distress proneness akin to the broad NA construct. This is consistent with prior reports that infant behavioral patterns attributed to sadness non-differentially predict all NA facets in later childhood (Putnam et al., 2008), and highlights the challenges inherent in attributing qualitatively distinct emotional states based on infant behavior (Barrett et al., 2019). 
A further consideration relates to the conceptualization of parent internalizing symptoms. Anxiety and depression are broad and comorbid constructs (Kessler et al., 2005). Only one study explored their interaction, finding stronger associations with infant NA for maternal depressive symptoms than anxiety, and no evidence of interaction (Rouse \& Goodman, 2014). Further research is needed to elucidate unique and joint contributions of each. Moreover, the heterogeneity of parental anxiety has not been explored in relation to infant NA. Dimensional approaches may clarify whether more nuanced internalizing constructs differentially predict conceptually aligned dimensions of infant NA.

\section{Does timing of parent internalizing symptoms or infant NA matter?}

In mothers, associations between internalizing symptoms and infant NA did not vary by timing of exposure across pregnancy and the postpartum, or by age of infant at time of NA assessment. Only one study examined preconception symptoms, replicating findings of preconception associations across two independent samples (Spry et al., 2019). Similar sized associations of maternal antenatal and postnatal symptoms are consistent with both the fetal programming and interpersonal stress transmission models. These explanations are not mutually exclusive; indeed, biopsychosocial models of temperament incorporate biological and social influences occurring both before and after birth (Goldsmith et al., 1987; Rothbart \& Derryberry, 1981).

Alternatively, given continuities of maternal depression and anxiety from preconception to perinatal (Patton et al., 2015) and from pregnancy to postpartum (Howard et al., 2014), associations at each phase may reflect confounding or mediation by earlier or later maternal symptoms. Studies that jointly modelled antenatal and postnatal symptoms mostly found independent associations with infant NA (Davis et al., 2004, 2007; Henrichs et al., 2009; Spry et al., 2019; Zhang et al., 2017). Given the small evidence base, further repeated-measures studies are needed. A further possible explanation is confounding. In the few studies with adjusted analyses, associations remained after adjustment for demographic and substance use factors (Erickson, 2018; Nomura et al., 2014, 2019; Spry et al., 2019; Zhang et al., 2017). Nonetheless, potential for confounding remains. For example, genetic factors may act as confounders by direct inheritance of predispositions to both internalizing symptoms and NA (Adams et al., 2019), and also influence infant NA via non-genetic mediational pathways including parental symptoms (Kong et al., 2018). Research using natural experiment designs may shed light on these potential influences (Thapar \& Rutter, 2019).

Findings in relation to paternal symptoms are preliminary given the small number of studies. However, it is notable that, like the maternal findings, these are consistent with both the fetal programming and interpersonal stress transmission models. The smaller association of antenatal 
symptoms with infant NA in fathers compared to mothers supports the fetal programming hypothesis, due to the lack of direct biological in utero programming in fathers (Gage et al., 2016; Thapar \& Rutter, 2019). Further, the association of paternal postnatal symptoms was much stronger than paternal antenatal symptoms, and similar in size to that observed for mothers, consistent with interpersonal stress transmission models. These models suggest that such postnatal paternal associations operate via multiple relational pathways including impacts on parenting, maternal mental health, and the broader family climate (Glasser \& Lerner-Geva, 2018; Narayanan \& Nærde, 2016). Potential confounding of paternal associations also remains plausible, though the different paternal ante- and postnatal associations are less consistent with this explanation (Gage et al., 2016).

\section{Assessment mode}

Our finding of no difference in strength of association by approach to assessing maternal symptoms was consistent with a prior review of older children (Goodman et al., 2011). We also found no evidence of effect modification by method of outcome assessment in mothers. This is in contrast to the common expectation of larger associations with parent-reported infant NA, due to shared method variance and the tendency for women with internalizing symptoms to describe their infants as more reactive (Luoma et al., 2004; Najman et al., 2001). Maternal report may provide a more valid index of NA, across settings and time, than laboratory assessments often conducted under artificial conditions (Bates et al., 2014; Rothbart \& Bates, 2006; Shiner \& Caspi, 2003). Notably, there was some variability of observer-rated effect sizes. Associations were larger in studies utilizing validated observational protocols and rating scales (Davis et al., 2007; Werner et al., 2007) than in those employing unvalidated or adapted protocols (de Weerth et al., 2013; Gustafsson et al., 2018; Leerkes \& Crockenberg, 2003). We were unable to address these questions for fathers.

\section{Strengths and limitations}

Our study has notable strengths. We used a rigorous methodology to search and evaluate literature. The protocol was preregistered, and data and code made publicly available in accordance with open science principles. By including the broad dimension of negative affectivity as well as its component facets, we provided a more nuanced understanding of how these may differentially relate to parental symptoms. Further, by examining both maternal and paternal internalizing symptoms across developmental windows, we indirectly addressed questions of mechanisms in order to advance theoretical understanding. 
Our review also has limitations. First, adjustments for confounders were few and inconsistently implemented. We therefore meta-analysed unadjusted results. While associations remained after adjustment for baseline confounders in the few studies with adjustments (Erickson, 2018; Nomura et al., 2014, 2019; Spry et al., 2019; Zhang et al., 2017), potential for confounding remains. Thus, we describe meaningful patterns of associations rather than draw causal conclusions (Hernán et al., 2015). The quality assessment also suggests possible bias due to non-representative sampling or missing data in some studies. Two of the five methods we used further suggested possible publication bias and, as with any review, residual publication bias remains likely. We only included studies published in English, which may limit generalizability, though around one third of included studies used data from non-English speaking countries.

\section{Future research directions}

Some aspects of our research questions could not be fully addressed due to limitations of the existing evidence base, representing key directions for future research.

Fathers. Associations between fathers' internalizing symptoms and infant NA are important for two reasons. First, comparison of maternal and paternal associations over time can inform our understanding of potential mechanisms and theoretical models. Secondly, links between fathers' internalizing symptoms and the early emotional development of their infants are important in their own right, given the prevalence of paternal perinatal depression and anxiety, evidence of associations with later child socio-emotional development, and the increasing role of fathers in the care of their infants. Yet only 40 estimates from 6 studies were available. Future research should prioritize assessment of both paternal and maternal symptoms, to facilitate comparison as well as investigating their potential interaction.

Preconception. A growing body of research links preconception parental characteristics with children's socio-emotional development. Various mechanisms have been proposed for these associations, including long-term impacts of chronic stress on reproductive biology, and ongoing difficulties with emotional and interpersonal regulation that persist into pregnancy and are associated with caregiving behavior even without postpartum symptoms. These possibilities carry important implications for our understanding of the intergenerational transmission of mental health risk. Yet only one study has examined prospective associations of maternal preconception internalizing symptoms with infant NA. This represents a key evidence gap. 


\section{Conclusions}

Overall, we found evidence that both maternal and paternal internalizing symptoms are associated with increased NA in infant offspring. While modest, associations in this review are meaningful at a population level, given high prevalence rates of perinatal depression and anxiety (Funder \& Ozer, 2019). Nonetheless, the size of observed associations also serve as a reminder that parental internalizing symptoms are only one of many developmental mechanisms that may contribute to infant NA (Cicchetti \& Rogosch, 1996). We found increased general distress-proneness in infants of parents with internalizing symptoms, as well as some specificity in patterning of NA facets. These findings underscore the value of considering both the overarching NA dimension and its facets when investigating pathways from parental symptoms to child socio-emotional development. Findings were consistent with both fetal programming and interpersonal stress transmission models, aligning with biopsychosocial models that propose multiple transmission pathways (Goldsmith et al., 1987; Rothbart \& Derryberry, 1981). Careful research design is needed to address questions of exposure continuity, confounding, and associated neurodevelopmental and relational processes, as well as evidence gaps regarding preconception processes and paternal symptoms. Greater understanding of underlying mechanisms will inform the nature and timing of interventions to promote good mental health in parents and enhance targeted early interventions for families at risk, ultimately reducing negative impacts on the mental health of the next generation. 


\section{Contributors}

ES conceptualized the article, developed the methodology, wrote the protocol, identified potential studies, cross-checked extracted data, assessed study quality, and drafted the manuscript. SA extracted the data and conducted the analysis. GY and ES supervised the analysis planning and implementation. CO reviewed the protocol and contributed to development of the methodology. All authors were involved in reviewing analyses, interpreting results, and critically revising the report.

\section{Funding}

ES was supported by an Australian Postgraduate Award. Research at the Murdoch Children's Research Institute is supported by the Victorian Government's Operational Infrastructure Program.

\section{Conflict of interest}

No conflict of interest declared.

\section{Acknowledgments}

The authors are grateful to Ms Poh Chua, at the Royal Children's Hospital, for her assistance in developing the systematic search strategy. 


\section{References}

Adams, M. J., Howard, D. M., Luciano, M., Clarke, T.-K., Davies, G., Hill, W. D., Smith, D., Deary, I. J., Porteous, D. J., \& McIntosh, A. M. (2019). Genetic stratification of depression by neuroticism: revisiting a diagnostic tradition. Psychological Medicine, 1-10. https://doi.org/10.1017/s0033291719002629

Alvik, A., Torgersen, A. M., Aalen, O. O., \& Lindemann, R. (2011). Binge alcohol exposure once a week in early pregnancy predicts temperament and sleeping problems in the infant. Early Human Development, 87(12), 827-833. https://doi.org/10.1016/j.earlhumdev.2011.06.009

Assink, C. J. M. (2016). Fitting three-level meta-analytic models in R: A step-by-step tutorial. The Quantitative Methods for Psychology, 12(3), 154-174. https://doi.org/10.20982/tqmp.12.3.p154

Baibazarova, E., van de Beek, C., Cohen-Kettenis, P. T., Buitelaar, J., Shelton, K. H., \& van Goozen, S. H. M. (2013). Influence of prenatal maternal stress, maternal plasma cortisol and cortisol in the amniotic fluid on birth outcomes and child temperament at 3 months. Psychoneuroendocrinology, 38(6), 907-915. https://doi.org/10.1016/j.psyneuen.2012.09.015

Barrett, L. F., Adolphs, R., Marsella, S., Martinez, A. M., \& Pollak, S. D. (2019). Emotional expressions reconsidered: Challenges to inferring emotion from human facial movements. Psychol Sci Public Interest, 20(1), 1-68. https://doi.org/10.1177/1529100619832930

Bates, J. E., Schermerhorn, A. C., \& Petersen, I. T. (2014). Temperament concepts in developmental psychopathology. In L. M. \& R. K. (Eds.), Handbook of developmental psychopathology (pp. 311-329). Springer.

Beck, C. T. (1996). A meta-analysis of the relationship between postpartum depression and infant temperament. Nursing Research and Practice, 45(4), 225-230. https://doi.org/10.1097/00006199-199607000-00006

Bhat, A., Chowdayya, R., Selvam, S., Khan, A., Kolts, R., \& Srinivasan, K. (2015). Maternal prenatal psychological distress and temperament in 1-4 month old infants - A study in a non-western population. Infant Behavior and Development, 39, 35-41. https://doi.org/10.1016/j.infbeh.2014.12.002

Borenstein, M., Hedges, L. V, Higgins, J. P. T., \& Rothstein, H. R. (2011). Introduction to meta- 
analysis. John Wiley \& Sons.

Borenstein, M., Higgins, J. P., Hedges, L. V, \& Rothstein, H. R. (2017). Basics of meta-analysis: I(2) is not an absolute measure of heterogeneity. Res Synth Methods, 8(1), 5-18. https://doi.org/10.1002/jrsm.1230

Bornstein, M. H., Putnick, D. L., Gartstein, M. A., Hahn, C. S., Auestad, N., \& O’Connor, D. L. (2015). Infant temperament: stability by age, gender, birth order, term status, and socioeconomic status. Child Dev, 86(3), 844-863. https://doi.org/10.1111/cdev.12367

Braithwaite, E. (2015). Antenatal mood disturbance and infant development : investigating neurobiological mechanisms of risk. internal-pdf://174.93.164.251/Braithwaite-2015.pdf

Bruder-Costello, B., Warner, V., Talati, A., Nomura, Y., Bruder, G., \& Weissman, M. (2007). Temperament among offspring at high and low risk for depression. Psychiatry Research, 153(2), 145-151. https://doi.org/10.1016/j.psychres.2007.02.013

Cameron, E. E., Sedov, I. D., \& Tomfohr-Madsen, L. M. (2016). Prevalence of paternal depression in pregnancy and the postpartum: an updated meta-analysis. J Affect Disord, 206, 189-203. https://doi.org/10.1016/j.jad.2016.07.044

Carranza Carnicero, J. A., Pérez-López, J., Del Carmen González Salinas, M., \& Martínez-Fuentes, M. T. (2000). A longitudinal study of temperament in infancy: Stability and convergence of measures. European Journal of Personality, 14(1), 21-37. https://doi.org/10.1002/(SICI)10990984(200001/02)14:1<21::AID-PER367>3.0.CO;2-A

Chan, J. C., Nugent, B. M., \& Bale, T. L. (2017). Parental advisory: maternal and paternal stress can impact offspring neurodevelopment. Biological Psychiatry, 83, 886-894. https://doi.org/10.1016/j.biopsych.2017.10.005

Chazan, R. Z. (1998). Great expectations: Mothers' prenatal beliefs and the mother-infant relationship: Vol. Doctor of [Yale University]. internal-pdf://239.33.165.57/Chazan-1998.pdf

Cicchetti, D., \& Rogosch, F. A. (1996). Equifinality and multifinality in developmental psychopathology. Development and Psychopathology, 8(4), 597-600. internalpdf://228.60.152.94/CicchettiRogoschDPP1996.pdf

Clauss, J. A., \& Blackford, J. U. (2012). Behavioral inhibition and risk for developing social anxiety 
disorder: A meta-analytic study. Journal of the American Academy of Child \& Adolescent Psychiatry, 51(10), 1066-1075. internalpdf://0389832616/08908567_S0890856712X00091_S0890856712005928_main.pdf

Connell, A. M., \& Goodman, S. H. (2002). The association between psychopathology in fathers versus mothers and children's internalizing and externalizing behavior problems: A meta-analysis. Psychological Bulletin, 128(5), 746-773. https://doi.org/10.1037/0033-2909.128.5.746

Coplan, R. J., O'Neil, K., \& Arbeau, K. A. (2005). Maternal anxiety during and after pregnancy and infant temperament at three months of age. Journal of Prenatal \& Perinatal Psychology \& Health, 19(3), 199-215. internal-pdf://133.102.165.182/Coplan-2005.pdf internalpdf://2534450661/Coplan-20051.pdf

Cuijpers, P., Smit, F., Penninx, B. W. J. H., de Graaf, R., ten Have, M., \& Beekman, A. T. F. \%J A. of G. P. (2010). Economic costs of neuroticism: a population-based study. 67(10), 1086-1093. https://doi.org/10.1001/archgenpsychiatry.2010.130

Davis, E. P., Glynn, L. M., Schetter, C. D., Hobel, C., Chicz-Demet, A., \& Sandman, C. A. (2007). Prenatal Exposure to Maternal Depression and Cortisol Influences Infant Temperament. Journal of the American Academy of Child \& Adolescent Psychiatry, 46(6), 737-746. https://doi.org/http://dx.doi.org/10.1097/chi.0b013e318047b775

Davis, E. P., Snidman, N., Wadhwa, P. D., Glynn, L. M., Schetter, C. D., \& Sandman, C. A. (2004). Prenatal maternal anxiety and depression predict negative behavioral reactivity in infancy. Infancy, 6(3), 319-331. https://doi.org/10.1207/s15327078in0603_1

de Weerth, C., Buitelaar, J. K., \& Beijers, R. (2013). Infant cortisol and behavioral habituation to weekly maternal separations: links with maternal prenatal cortisol and psychosocial stress. Psychoneuroendocrinology, 38(12), 2863-2874. https://doi.org/10.1016/j.psyneuen.2013.07.014

Della Vedova, A. M. (2014). Maternal psychological state and infant's temperament at three months. Journal of Reproductive \& Infant Psychology, 32(5), 520-534. https://doi.org/10.1080/02646838.2014.947472

Downes, M. J., Brennan, M. L., Williams, H. C., \& Dean, R. S. (2016). Development of a critical appraisal tool to assess the quality of cross-sectional studies (AXIS). BMJ Open, 6(12), e011458. https://doi.org/10.1136/bmjopen-2016-011458 
Edwards, E. S., Holzman, J. B., Burt, N. M., Rutherford, H. J. V, Mayes, L. C., \& Bridgett, D. J. (2017). Maternal Emotion Regulation Strategies, Internalizing Problems and Infant Negative Affect. J Appl Dev Psychol, 48, 59-68. https://doi.org/10.1016/j.appdev.2016.12.001

Erickson, N. L. (2018). Prenatal origins of infant temperament: Exploring interrelationships between pregnancy anxiety, physiological stress, and maternal attachment status (Vol. 79) [ProQuest Information \& Learning]. internal-pdf://170.38.166.83/Erickson-2018.pdf

Erickson, N. L., Gartstein, M. A., \& Dotson, J. A. W. (2017). Review of prenatal maternal mental health and the development of infant temperament. Journal of Obstetric, Gynecologic \& Neonatal Nursing, 46(4), 588-600. https://doi.org/10.1016/j.jogn.2017.03.008

Erickson, N. L., Hancock, G. R., Oberlander, T. F., Brain, U., Grunau, R. E., \& Gartstein, M. A. (2019). Prenatal SSRI antidepressant use and maternal internalizing symptoms during pregnancy and postpartum: Exploring effects on infant temperament trajectories for boys and girls. Journal Of Affective Disorders, 258, 179-194. https://doi.org/10.1016/j.jad.2019.08.003

Fernandes, M., Srinivasan, K., Menezes, G., \& Ramchandani, P. G. (2018). Prenatal depression, fetal neurobehavior, and infant temperament: Novel insights on early neurodevelopment from a socioeconomically disadvantaged Indian cohort. Development And Psychopathology, 30(3), 725-742. https://doi.org/10.1017/S0954579418000615

Field, T. (2011). Prenatal depression effects on early development: a review. Infant Behav Dev, 34(1), 1-14. https://doi.org/10.1016/j.infbeh.2010.09.008

Fisher, Z., Tipton, E., \& Zhipeng, H. (2017). robumeta (1.8).

Forman, D. R., O'Hara, M. W., Stuart, S., Gorman, L. L., Larsen, K. E., \& Coy, K. C. (2007). Effective treatment for postpartum depression is not sufficient to improve the developing mother-child relationship. Development And Psychopathology, 19(2), 585-602. https://doi.org/10.1017/s0954579407070289

Frost, L. A. (1996). Postpartum distress in fathers: predicting depressive symptoms, anxiety and anger at one month postpartum [University of Wisconsin--Madison]. internalpdf://63.136.166.176/Frost 1996.pdf

Funder, D. C., \& Ozer, D. J. (2019). Evaluating effect size in psychological research: sense and nonsense. Advances in Methods and Practices in Psychological Science, 2515245919847202. 
https://doi.org/10.1177/2515245919847202

Gage, S. H., Munafo, M. R., \& Davey Smith, G. (2016). Causal Inference in Developmental Origins of Health and Disease (DOHaD) Research. Annu Rev Psychol, 67, 567-585. https://doi.org/10.1146/annurev-psych-122414-033352

Gartstein, M. A., \& Hancock, G. R. (2019). Temperamental growth in infancy: Demographic, maternal symptom, and stress contributions to overarching and fine-grained dimensions. Merrill-Palmer Quarterly, 65(2), 121-157. internal-pdf://0238962600/Gartstein 2019.pdf

Gartstein, M. A., \& Rothbart, M. K. (2003). Studying infant temperament via the revised infant behavior questionnaire. Infant Behavior \& Development, 26(1), 64-86. https://doi.org/10.1016/s0163-6383(02)00169-8

Glasser, S., \& Lerner-Geva, L. (2018). Focus on fathers: paternal depression in the perinatal period. Perspectives in Public Health, 1757913918790597. https://doi.org/10.1177/1757913918790597

Glover, V. (2011). Annual Research Review: Prenatal stress and the origins of psychopathology: an evolutionary perspective. J Child Psychol Psychiatry, 52(4), 356-367. https://doi.org/10.1111/j.1469-7610.2011.02371.x

Goldsmith, H. H., Buss, A. H., Plomin, R., Rothbart, M. K., Thomas, A., Chess, S., Hinde, R. A., \& McCall, R. B. (1987). Roundtable: What is temperament? Four approaches. Child Development, 505-529. https://doi.org/10.2307/1130527

Goodman, S. H. (2020). Intergenerational Transmission of Depression. Annu Rev Clin Psychol, 16, 213-238. https://doi.org/10.1146/annurev-clinpsy-071519-113915

Goodman, S. H., Rouse, M. H., Connell, A. M., Broth, M. R., Hall, C. M., \& Heyward, D. (2011). Maternal depression and child psychopathology: a meta-analytic review. Clin Child Fam Psychol Rev, 14(1), 1-27. https://doi.org/10.1007/s10567-010-0080-1

Granat, A., Gadassi, R., Gilboa-Schechtman, E., \& Feldman, R. \%J E. (2017). Maternal depression and anxiety, social synchrony, and infant regulation of negative and positive emotions. 17(1), 11. https://doi.org/10.1037/emo0000204

Gunnar, M. R., \& Davis, E. P. (2013). The Effects of Stress on Early Brain and Behavioral Development. In J. L. R. Rubenstein \& P. Rakic (Eds.), Neural Circuit Development and Function 
in the Brain: Comprehensive Developmental Neuroscience (Vol. 3, pp. 447-465). Academic Press. https://doi.org/10.1016/b978-0-12-397267-5.00063-7

Gustafsson, H. C., Sullivan, E. L., Nousen, E. K., Sullivan, C. A., Huang, E., Rincon, M., Nigg, J. T., \& Loftis, J. M. (2018). Maternal prenatal depression predicts infant negative affect via maternal inflammatory cytokine levels. Brain Behav Immun, 73, 470-481. https://doi.org/10.1016/j.bbi.2018.06.011

Gutierrez-Galve, L., Stein, A., Hanington, L., Heron, J., \& Ramchandani, P. G. (2015). Paternal depression in the postnatal period and child development: mediators and moderators. Pediatrics, 135(2), e339-47. https://doi.org/10.1542/peds.2014-2411

Hammen, C., Shih, J. H., \& Brennan, P. A. (2004). Intergenerational transmission of depression: test of an interpersonal stress model in a community sample. J Consult Clin Psychol, 72(3), 511-522. https://doi.org/10.1037/0022-006X.72.3.511

Hankin, B. L., Snyder, H. R., Gulley, L. D., Schweizer, T. H., Bijttebier, P., Nelis, S., Toh, G., \& Vasey, M. W. (2016). Understanding comorbidity among internalizing problems: Integrating latent structural models of psychopathology and risk mechanisms. Dev Psychopathol, 28(4pt1), 9871012. https://doi.org/10.1017/S0954579416000663

Hedges, L. V, Tipton, E., \& Johnson, M. C. (2010). Robust variance estimation in meta-regression with dependent effect size estimates. Research Synthesis Methods, 1(1), 39-65. https://doi.org/10.1002/jrsm.5

Henrichs, J., Schenk, J. J., Schmidt, H. G., Velders, F. P., Hofman, A., Jaddoe, V. W. V, Verhulst, F. C., \& Tiemeier, H. (2009). Maternal pre- and postnatal anxiety and infant temperament: The Generation R Study. Infant and Child Development, 18, 556-572. https://doi.org/10.1002/Icd.639

Hernán, M. A., Hsu, J., \& Healy, B. (2015). A second chance to get causal inference right: A classification of data science tasks. Chance, 32(1), 42-49. https://doi.org/10.1080/09332480.2019.1579578

Hipwell, A. E., Tung, I., Northrup, J., \& Keenan, K. (2019). Transgenerational associations between maternal childhood stress exposure and profiles of infant emotional reactivity. Development and Psychopathology, 1-12. https://doi.org/10.1017/s0954579419000324 
Howard, L. M., Molyneaux, E., Dennis, C.-L., Rochat, T., Stein, A., \& Milgrom, J. (2014). Non-psychotic mental disorders in the perinatal period. The Lancet, 384(9956), 1775-1788. https://doi.org/10.1016/s0140-6736(14)61276-9

IntHout, J., loannidis, J. P., Rovers, M. M., \& Goeman, J. J. (2016). Plea for routinely presenting prediction intervals in meta-analysis. BMJ Open, 6(7), e010247. https://doi.org/10.1136/bmjopen-2015-010247

Isosävi, S., Diab, S. Y., Kangaslampi, S., Qouta, S., Kankaanpää, S., Puura, K., \& Punamäki, R. (2017). Maternal trauma affects prenatal mental health and infant stress regulation among Palestinian dyads. Infant Mental Health Journal, 38(5), 617-633. https://doi.org/10.1002/imhj.21658

Jonas, W., Atkinson, L., Steiner, M., Meaney, M. J., Wazana, A., \& Fleming, A. S. (2015). Breastfeeding and maternal sensitivity predict early infant temperament. Acta Paediatrica, 104(7), 678-686. https://doi.org/10.1111/apa.12987

Jover, M., Colomer, J., Carot, J. M., Larsson, C., Bobes, M. T., Ivorra, J. L., Martín-Brufau, R., \& Sanjuan, J. (2014). Maternal anxiety following delivery, early infant temperament and mother's confidence in caregiving. The Spanish Journal Of Psychology, 17, E95-E95. https://doi.org/10.1017/sjp.2014.87

Kagan, J., Snidman, N. C., Zentner, M., \& Peterson, E. (1999). Infant temperament and anxious symptoms in school age children. Development and Psychopathology, 11(02), 209-224. https://doi.org/10.1017/s0954579499002023

Kagan, J., Snidman, N., Kahn, V., Towsley, S., Steinberg, L., \& Fox, N. A. (2007). The preservation of two infant temperaments into adolescence. Monographs of the Society for Research into Child Development, 72(2), 1-95. https://doi.org/10.1111/j.1540-5834.2007.00436.x

Keenan, K., Hipwell, A. E., Class, Q. A., \& Mbayiwa, K. (2018). Extending the developmental origins of disease model: Impact of preconception stress exposure on offspring neurodevelopment. Developmental Psychobiology, 60(7), 753-764. https://doi.org/10.1002/dev.21773

Kessler, R. C., Chiu, W. T., Demler, O., \& Walters, E. E. (2005). Prevalence, severity, and comorbidity of 12-month dsm-iv disorders in the national comorbidity survey replication. Archives of General Psychiatry, 62(6), 617-627. https://doi.org/10.1001/archpsyc.62.6.617

Kessler, R. C., Sampson, N. A., Berglund, P., Gruber, M. J., Al-Hamzawi, A., Andrade, L., Bunting, B., 
Demyttenaere, K., Florescu, S., De Girolamo, G. \%J E., \& sciences, psychiatric. (2015). Anxious and non-anxious major depressive disorder in the World Health Organization World Mental Health Surveys. 24(3), 210-226. https://doi.org/10.1017/s2045796015000189

Kim, Y., Bird, A., Peterson, E., Underwood, L., Morton, S. M. B., \& Grant, C. C. (2020). Maternal Antenatal Depression and Early Childhood Sleep: Potential Pathways Through Infant Temperament. Journal of Pediatric Psychology, 45(2), 203-217. https://doi.org/10.1093/jpepsy/jsaa001

Klengel, T., Dias, B. G., \& Ressler, K. J. (2015). Models of intergenerational and transgenerational transmission of risk for psychopathology in mice. Neuropsychopharmacology, 41(1), 219-231. internal-pdf://96.207.59.242/Klengel_Dias_Intergenerational Review2015Neuro.pdf

Kong, A., Thorleifsson, G., Frigge, M. L., Vilhjalmsson, B. J., Young, A. I., Thorgeirsson, T. E., Benonisdottir, S., Oddsson, A., Halldorsson, B. V, \& Masson, G. \%J S. (2018). The nature of nurture: Effects of parental genotypes. 359(6374), 424-428. https://doi.org/10.1101/219261

Korja, R., Nolvi, S., Kataja, E. L., Scheinin, N., Junttila, N., Lahtinen, H., Saarni, S., Karlsson, L., \& Karlsson, H. (2018). The courses of maternal and paternal depressive and anxiety symptoms during the prenatal period in the FinnBrain Birth Cohort study. PLoS One, 13(12), e0207856. https://doi.org/10.1371/journal.pone.0207856

Kotov, R., Gamez, W., Schmidt, F., \& Watson, D. (2010). Linking "big" personality traits to anxiety, depressive, and substance use disorders: a meta-analysis. Psychological Bulletin, 136(5), 768.

Kukkonen, E. (2019). Parental negative affect and postnatal depressive symptoms. Psychology, December. https://www.utupub.fi/bitstream/handle/10024/148766/Kukkonen_Elina_opinnayte.pdf?sequ ence $=1$

Lahey, B. B. (2009). Public health significance of neuroticism. American Psychologist, 64(4), 241. https://doi.org/10.1037/a0015309

Leerkes, E. M., \& Crockenberg, S. C. (2003). The impact of maternal characteristics and sensitivity on the concordance between maternal reports and laboratory observations of infant negative emotionality. Infancy, 4(4), 517-539. https://doi.org/10.1207/S15327078IN0404_07

Lemola, S., Stadlmayr, W., \& Grob, A. (2009). Infant irritability: The impact of fetal alcohol exposure, 
maternal depressive symptoms, and low emotional support from the husband. Infant Mental Health Journal, 30(1), 57-81. https://doi.org/10.1002/imhj.20203

Letcher, P., Smart, D., Sanson, A., \& Toumbourou, J. W. (2009). Psychosocial precursors and correlates of differing internalizing trajectories from 3 to 15 years. Social Development, 18(3), 618-646. https://doi.org/10.1111/j.1467-9507.2008.00500.x

Luecken, L. J., MacKinnon, D. P., Jewell, S. L., Crnic, K. A., \& Gonzales, N. A. (2015). Effects of prenatal factors and temperament on infant cortisol regulation in low-income Mexican American families. Developmental Psychobiology, 57(8), 961-973. https://doi.org/10.1002/dev.21328

Luoma, I., Kaukonen, P., Mäntymaa, M., Puura, K., Tamminen, T., \& Salmelin, R. (2004). A longitudinal study of maternal depressive symptoms, negative expectations and perceptions of child problems. Child Psychiatry and Human Development, 35(1), 37-53. https://doi.org/10.1023/b:chud.0000039319.96151.63

Madigan, S., Oatley, H., Racine, N., Fearon, R. M. P., Schumacher, L., Akbari, E., Cooke, J. E., \& Tarabulsy, G. M. (2018). A meta-analysis of maternal prenatal depression and anxiety on child socioemotional development. Journal of the American Academy of Child \& Adolescent Psychiatry, 57(9), 645-657.e8. https://doi.org/https://doi.org/10.1016/j.jaac.2018.06.012

McLean, M. A., Cobham, V. E., Simcock, G., Kildea, S., \& King, S. (2019). Toddler temperament mediates the effect of prenatal maternal stress on childhood anxiety symptomatology: The QF2011 queensland flood study. International Journal of Environmental Research and Public Health, 16(11). https://doi.org/10.3390/ijerph16111998

Meaney, M. J., \& Szyf, M. (2005). Environmental programming of stress responses through DNA methylation: life at the interface between a dynamic environment and a fixed genome. Dialogues in Clinical Neuroscience, 7(2), 103. internalpdf://139.166.161.115/DialoguesClinNeurosci-7-103.pdf

Metz, M., Majdandžić, M., \& Bögels, S. (2018). Concurrent and Predictive Associations Between Infants' and Toddlers' Fearful Temperament, Coparenting, and Parental Anxiety Disorders. Journal of Clinical Child and Adolescent Psychology, 47(4), 569-580. https://doi.org/10.1080/15374416.2015.1121823

Moher, D., Liberati, A., Tetzlaff, J., Altman, D. G., \& Group, P. (2009). Preferred reporting items for systematic reviews and meta-analyses: the PRISMA statement. PLoS Medicine, 6(7), e1000097. 
https://doi.org/10.7717/peerj.4598/supp-5

Moscardino, U., Axia, G., \& Altoè, G. (2006). The role of maternal depressed mood and behavioural soothing on infant response to routine vaccination. Acta Paediatrica (Oslo, Norway: 1992), 95(12), 1680-1684. https://doi.org/10.1080/08035250600764818

Muris, P., \& Ollendick, T. H. (2005). The role of temperament in the etiology of child psychopathology. Clin Child Fam Psychol Rev, 8(4), 271-289. https://doi.org/10.1007/s10567005-8809-y

Najman, J. M., Williams, G. M., Nikles, J., Spence, S., Bor, W., O'Callaghan, M., Le Brocque, R., Andersen, M. J., \& Shuttlewood, G. J. (2001). Bias influencing maternal reports of child behaviour and emotional state. Social Psychiatry and Psychiatric Epidemiology, 36(4), 186-194. https://doi.org/10.1007/s001270170062

Narayanan, M. K., \& Nærde, A. (2016). Associations between maternal and paternal depressive symptoms and early child behavior problems: Testing a mutually adjusted prospective longitudinal model. Journal of Affective Disorders, 196, 181-189.

https://doi.org/10.1016/j.jad.2016.02.020

National Heart Lung and Blood Institute: National Institutes of Health. (2014). Quality Assessment Tool for Observational Cohort and Cross-Sectional Studies. https://www.nhlbi.nih.gov/healthtopics/study-quality-assessment-tools

Natsuaki, M. N., Shaw, D. S., Neiderhiser, J. M., Ganiban, J. M., Harold, G. T., Reiss, D., \& Leve, L. D. (2014). Raised by depressed parents: is it an environmental risk? Clin Child Fam Psychol Rev, 17(4), 357-367. https://doi.org/10.1007/s10567-014-0169-z

Newland, R. P., Parade, S. H., Dickstein, S., \& Seifer, R. (2016). The association between maternal depression and sensitivity: Child-directed effects on parenting during infancy. Infant Behavior and Development, 45, 47-50. https://doi.org/10.1016/j.infbeh.2016.09.001

Nolvi, S., Karlsson, L., Bridgett, D. J., Korja, R., Huizink, A. C., Kataja, E. L., \& Karlsson, H. (2016). Maternal prenatal stress and infant emotional reactivity six months postpartum. J Affect Disord, 199, 163-170. https://doi.org/10.1016/j.jad.2016.04.020

Nomura, Y., Davey, K., Pehme, P. M., Finik, J., Glover, V., Zhang, W., Huang, Y., Buthmann, J., Dana, K., Yoshida, S., Tsuchiya, K. J., Li, X. B., \& Ham, J. (2019). Influence of in utero exposure to 
maternal depression and natural disaster-related stress on infant temperament at 6 months: The children of Superstorm Sandy. Infant Mental Health Journal, 40(2), 204-216. https://doi.org/10.1002/imhj.21766

Nomura, Y., Finik, J., Salzbank, J., Ly, J., Huynh, N., Davey, T., Dineva, M., Abelow, A., Flores, C., Daniel, R., Loudon, H., Stone, J., Pierre, P., Eglinton, G., \& Newcorn, J. H. (2014). The Effects of Preeclampsia on Perinatal Risks and Infant Temperaments Among Mothers With Antenatal Depression. Psychology Research, 4(6), 451-461. https://doi.org/10.17265/2159$5542 / 2014.06 .005$

O'Connor, T. G., Monk, C., \& Fitelson, E. M. (2014). Practitioner review: maternal mood in pregnancy and child development--implications for child psychology and psychiatry. J Child Psychol Psychiatry, 55(2), 99-111. https://doi.org/10.1111/jcpp.12153

Patton, G. C., Romaniuk, H., Spry, E., Coffey, C., Olsson, C., Doyle, L. W., Oats, J., Hearps, S., Carlin, J. B., \& Brown, S. (2015). Prediction of perinatal depression from adolescence and before conception (VIHCS): 20-year prospective cohort study. The Lancet, 386(9996), 875-883. https://doi.org/10.1016/s0140-6736(14)62248-0

Paulson, J. F., \& Bazemore, S. D. (2010). Prenatal and postpartum depression in fathers and its association with maternal depression: a meta-analysis. Jama, 303(19), 1961-1969. https://doi.org/10.1001/jama.2010.605

Peltola, M. J., Mäkelä, T., Paavonen, E. J., Vierikko, E., Saarenpää-Heikkilä, O., Paunio, T., Hietanen, J. K., \& Kylliäinen, A. \%J D. psychobiology. (2017). Respiratory sinus arrhythmia moderates the impact of maternal prenatal anxiety on infant negative affectivity. 59(2), 209-216. https://doi.org/10.1002/dev.21483

Penninx, B. W., Nolen, W. A., Lamers, F., Zitman, F. G., Smit, J. H., Spinhoven, P., Cuijpers, P., de Jong, P. J., van Marwijk, H. W., van der Meer, K., Verhaak, P., Laurant, M. G., de Graaf, R., Hoogendijk, W. J., van der Wee, N., Ormel, J., van Dyck, R., \& Beekman, A. T. (2011). Two-year course of depressive and anxiety disorders: results from the Netherlands Study of Depression and Anxiety (NESDA). J Affect Disord, 133(1-2), 76-85. https://doi.org/10.1016/j.jad.2011.03.027

Petzoldt, J., Wittchen, H. U., Einsle, F., \& Martini, J. (2015). Maternal anxiety versus depressive disorders: specific relations to infants' crying, feeding and sleeping problems. Child: Care, 
Health and Development, n/a-n/a. https://doi.org/10.1111/cch.12292

Pickens, J., \& Field, T. (1993). Facial expressivity in infants of depressed mothers. Developmental Psychology, 29(6), 986. https://doi.org/10.1037/0012-1649.29.6.986

Planalp, E. M., \& Goldsmith, H. H. (2019). Observed Profiles of Infant Temperament: Stability, Heritability, and Associations With Parenting. Child Dev. https://doi.org/10.1111/cdev.13277

Pluess, M., Velders, F. P., Belsky, J., van ljzendoorn, M. H., Bakermans-Kranenburg, M. J., Jaddoe, V. W. V, Hofman, A., Arp, P. P., Verhulst, F. C., \& Tiemeier, H. (2011). Serotonin transporter polymorphism moderates effects of prenatal maternal anxiety on infant negative emotionality. Biological Psychiatry, 69(6), 520-525. https://doi.org/10.1016/j.biopsych.2010.10.006

Potapova, N. V., Gartstein, M. A., \& Bridgett, D. J. (2014). Paternal influences on infant temperament: Effects of father internalizing problems, parenting-related stress, and temperament. Infant Behavior and Development, 37(1), 105-110. https://doi.org/10.1016/j.infbeh.2013.12.014

Prino, L. E., Rollè, L., Sechi, C., Patteri, L., Ambrosoli, A., Caldarera, A. M., Gerino, E., \& Brustia, P. (2016). Parental relationship with twins from pregnancy to 3 months: the relation among parenting stress, infant temperament, and well-being. Frontiers In Psychology, 7, 1628. https://doi.org/0.3389/fpsyg.2016.01628

Pustejovsky, J. (2020). clubSandwich: Cluster-robust (sandwich) variance estimators with smallsample corrections. $R$ package version 0.4.2.

Putnam, S. P., Rothbart, M. K., \& Gartstein, M. A. (2008). Homotypic and heterotypic continuity of fine-grained temperament during infancy, toddlerhood, and early childhood. Infant Child Development, 17(4), 387-405. https://doi.org/10.1002/icd.582

Putnam, S. P., Sanson, A. V, \& Rothbart, M. K. (2002). Child temperament and parenting. In M. H. Bornstein (Ed.), Handbook of parenting (Vol. 1, pp. 255-277). Lawrence Erlbaum Associates.

R Core Team. (2018). R: A language and environment for statistical computing. R Foundation for Statistical Computing. http://www.r-project.org/

Ramchandani, P. G., \& Psychogiou, L. (2009). Paternal psychiatric disorders and children's psychosocial development. The Lancet, 374(9690), 646-653. https://doi.org/10.1016/s0140- 


\section{$6736(09) 60238-5$}

Richters, J. E. (1992). Depressed mothers as informants about their children: A critical review of the evidence for distortion. Psychological Bulletin, 112(3), 485-499. https://doi.org/10.1037/00332909.112.3.485

Rothbart, M. K. (2004). Temperament and the pursuit of an integrated developmental psychology. Merrill-Palmer Quarterly, 50(4), 492-505. https://doi.org/10.1353/mpq.2004.0035

Rothbart, M. K., Ahadi, S. A., \& Evans, D. E. (2000). Temperament and personality: origins and outcomes. Journal of Personality and Social Psychology, 78(1), 122. https://doi.org/10.1037/0022-3514.78.1.122

Rothbart, M. K., \& Bates, J. E. (2006). Temperament. In H. D. Grotevant, W. Damon, \& N. Eisenberg (Eds.), Handbook of child psychology: Vol. 3. Social, emotional, and personality development (pp. 99-166). Wiley.

Rothbart, M. K., \& Derryberry, D. (1981). Development of individual differences in temperament. In M. E. Lamb \& A. L. Brown (Eds.), Advances in developmental psychology (Vol. 1). Earlbaum.

Rouse, M. H., \& Goodman, S. H. (2014). Perinatal depression influences on infant negative affectivity: timing, severity, and co-morbid anxiety. Infant Behavior and Development, 37(4), 739-751. https://doi.org/10.1016/j.infbeh.2014.09.001

Sanger, C., Iles, J. E., Andrew, C. S., \& Ramchandani, P. G. (2015). Associations between postnatal maternal depression and psychological outcomes in adolescent offspring: a systematic review. Arch Womens Ment Health, 18(2), 147-162. https://doi.org/10.1007/s00737-014-0463-2

Shackman, A. J., Tromp, D. P. M., Stockbridge, M. D., Kaplan, C. M., Tillman, R. M., \& Fox, A. S. (2016). Dispositional negativity: An integrative psychological and neurobiological perspective. Psychol Bull, 142(12), 1275-1314. https://doi.org/10.1037/bul0000073

Sharp, H., Pickles, A., Meaney, M., Marshall, K., Tibu, F., \& Hill, J. (2012). Frequency of infant stroking reported by mothers moderates the effect of prenatal depression on infant behavioural and physiological outcomes. PLoS One, 7(10), e45446. https://doi.org/10.1371/journal.pone.0045446

Shiner, R., \& Caspi, A. (2003). Personality differences in childhood and adolescence: Measurement, 
development, and consequences. Journal of Child Psychology and Psychiatry, 44(1), 2-32. https://doi.org/10.1111/1469-7610.00101

Spry, E., Moreno-Betancur, M., Becker, D., Romaniuk, H., Carlin, J. B., Molyneaux, E., Howard, L. M., Ryan, J., Letcher, P., McIntosh, J., Macdonald, J. A., Greenwood, C. J., Thomson, K. C., McAnally, H., Hancox, R., Hutchinson, D. M., Youssef, G. J., Olsson, C. A., \& Patton, G. C. (2019). Maternal mental health and infant emotional reactivity: a 20-year two-cohort study of preconception and perinatal exposures. Psychological Medicine, 1-11. https://doi.org/10.1017/S0033291719000709

Stanton, K., \& Watson, D. (2014). Positive and negative affective dysfunction in psychopathology. Social and Personality Psychology Compass, 8(9), 555-567.

Stein, A., Pearson, R. M., Goodman, S. H., Rapa, E., Rahman, A., McCallum, M., Howard, L. M., \& Pariante, C. M. (2014). Effects of perinatal mental disorders on the fetus and child. The Lancet, 384(9956), 1800-1819. https://doi.org/10.1016/s0140-6736(14)61277-0

Stenberg, C. R., \& Campos, J. J. (1990). The development of anger expressions in infancy. Psychological and Biological Approaches to Emotion, 247, 82.

Sugawara, M., Kitamura, T., Toda, M. A., \& Shima, S. (1999). Longitudinal relationship between maternal depression and infant temperament in a Japanese population. Journal Of Clinical Psychology, 55(7), 869-880. https://doi.org/10.1002/(sici)1097-4679(199907)55:7<869::aidjclp8>3.0.co;2-f

Sweeney, S., \& MacBeth, A. (2016). The effects of paternal depression on child and adolescent outcomes: A systematic review. Journal of Affective Disorders, 205, 44-59. https://doi.org/10.1016/j.jad.2016.05.073

Thapar, A., \& Rice, F. (2020). Family-based designs that disentangle inherited factors from pre-and postnatal environmental exposures: In vitro fertilization, discordant sibling pairs, maternal versus paternal comparisons, and adoption designs. Cold Spring Harbor Perspectives in Medicine, a038877. https://doi.org/10.1101/cshperspect.a038877

Thapar, A., \& Rutter, M. (2019). Do natural experiments have an important future in the study of mental disorders? Psychol Med, 49(7), 1079-1088. https://doi.org/10.1017/\$0033291718003896 
Thomas, E., Buss, C., Rasmussen, J. M., Entringer, S., Ramirez, J. S. B., Marr, M., Rudolph, M. D., Gilmore, J. H., Styner, M., Wadhwa, P. D., Fair, D. A., \& Graham, A. M. (2019). Newborn amygdala connectivity and early emerging fear. Developmental Cognitive Neuroscience, 37(July 2018), 100604. https://doi.org/10.1016/j.dcn.2018.12.002

Thomas, J. C., Letourneau, N., Campbell, T. S., Tomfohr-Madsen, L., Giesbrecht, G. F., \& Team, A. P. S. (2017). Developmental origins of infant emotion regulation: Mediation by temperamental negativity and moderation by maternal sensitivity. Dev Psychol, 53(4), 611-628. https://doi.org/10.1037/dev0000279

Ting, Y. (2012). Paternal depression and anxiety: Risk factors and adverse impact on infant temperament and development: Vol. Master of [University of Hong Kong]. internalpdf://188.142.143.207/Lee 2012.pdf

Tipton, E. (2015). Small sample adjustments for robust variance estimation with meta-regression. Psychological Methods, 20(3), 375. https://doi.org/10.1037/met0000011

Tipton, E., \& Pustejovsky, J. E. (2015). Small-Sample Adjustments for Tests of Moderators and Model Fit Using Robust Variance Estimation in Meta-Regression. Journal of Educational and Behavioral Statistics, 40(6), 604-634. https://doi.org/10.3102/1076998615606099

Valentine, J. C., Pigott, T. D., \& Rothstein, H. R. (2010). How Many Studies Do You Need? Journal of Educational and Behavioral Statistics, 35(2), 215-247. https://doi.org/10.3102/1076998609346961

van den Berg, M. P., van der Ende, J., Crijnen, A. A., Jaddoe, V. W., Moll, H. A., Mackenbach, J. P., Hofman, A., Hengeveld, M. W., Tiemeier, H., \& Verhulst, F. C. (2009). Paternal depressive symptoms during pregnancy are related to excessive infant crying. Pediatrics, 124(1), e96-103. https://doi.org/10.1542/peds.2008-3100

Van den Bergh, B. R. H., van den Heuvel, M. I., Lahti, M., Braeken, M., de Rooij, S. R., Entringer, S., Hoyer, D., Roseboom, T., Raikkonen, K., King, S., Schwab, M., Räikkönen, K., King, S., \& Schwab, M. (2017). Prenatal developmental origins of behavior and mental health: The influence of maternal stress in pregnancy. Neuroscience and Biobehavioral Reviews. https://doi.org/10.1016/j.neubiorev.2017.07.003

van den Heuvel, M. I., Johannes, M. A., Henrichs, J., \& Van den Bergh, B. R. H. (2015). Maternal mindfulness during pregnancy and infant socio-emotional development and temperament: the 
mediating role of maternal anxiety. Early Human Development, 91(2), 103-108.

https://doi.org/10.1016/j.earlhumdev.2014.12.003

Warner, V., \& Weissman, M. (2013). Intergenerational transmission. In K. C. Koenen, S. Rudenstine, E. Susser, \& S. Galea (Eds.), A Life Course Approach to Mental Disorders. Oxford University Press.

Werner, E. A., Myers, M. M., Fifer, W. P., Cheng, B., Fang, Y., Allen, R., \& Monk, C. (2007). Prenatal predictors of infant temperament. Dev Psychobiol, 49(5), 474-484.

https://doi.org/10.1002/dev.20232

Woody, C. A., Ferrari, A. J., Siskind, D. J., Whiteford, H. A., \& Harris, M. G. (2017). A systematic review and meta-regression of the prevalence and incidence of perinatal depression. Journal of Affective Disorders, 219, 86-92. https://doi.org/10.1016/j.jad.2017.05.003

Yim, I. S., Tanner Stapleton, L. R., Guardino, C. M., Hahn-Holbrook, J., \& Dunkel Schetter, C. (2015). Biological and Psychosocial Predictors of Postpartum Depression: Systematic Review and Call for Integration. Annual Review of Clinical Psychology, 11(1), 99-137. https://doi.org/10.1146/annurev-clinpsy-101414-020426

Zhang, W., Finik, J., Dana, K., Glover, V., Ham, J., \& Nomura, Y. (2017). Prenatal depression and infant temperament: The moderating role of placental gene expression. Infancy.

https://doi.org/10.1111/infa.12215 


\begin{tabular}{|c|c|c|}
\hline Construct & Definition $^{a}$ & Coded constructs ${ }^{b}$ \\
\hline Negative affectivity & $\begin{array}{l}\text { General tendency to experience negative affect, including sadness, fear, frustration and } \\
\text { lower rate of recovery. }\end{array}$ & $\begin{array}{l}\text { Negative affectivity (CCTI, IBQ, IBQ-R, IBQ-R } \\
\text { VSF) } \\
\text { Negative reactivity (DTS, ITSC, HIBRP, still- } \\
\text { face/infant negative expression and } \\
\text { vocalizations, maternal separation/negative } \\
\text { vocalizations) } \\
\text { Negative reactivity (ECBQ) } \\
\text { Reactivity (STST) } \\
\text { Mood (EITQ) }\end{array}$ \\
\hline \multicolumn{3}{|l|}{ Facet dimensions } \\
\hline Sadness & $\begin{array}{l}\text { Lowered mood and activity in relation to experience of suffering, physical state, object loss, } \\
\text { or inability to perform a desired action; general low mood. } \\
\text { "Did the baby seem sad when the caregiver was gone for an unusually long period of time? }\end{array}$ & Sadness (IBQ-R) \\
\hline $\begin{array}{l}\text { Frustration } \\
\text { / irritability }\end{array}$ & $\begin{array}{l}\text { Showing distress (e.g., crying or fussing) while (a) confined or restricted to a place; (b) } \\
\text { involved in normal caregiving activities (e.g., face washing); or (c) unable to perform a } \\
\text { desired action. } \\
\text { "When placed on his/her back, how often did the baby fuss or protest?" }\end{array}$ & $\begin{array}{l}\text { Frustration tolerance (TTS, RITQ) } \\
\text { Distress to limitations (IBQ, IBQ-R, arm } \\
\text { restraint/negative affective expression and } \\
\text { vocalizations) } \\
\text { Irritability (MABS) }\end{array}$ \\
\hline $\begin{array}{l}\text { Slow recovery } \\
\text { from distress }\end{array}$ & $\begin{array}{l}\text { Rate of recovery from peak distress, excitement, or general arousal= } \\
\text { "When frustrated with something, how often did the baby calm down within } 5 \text { minutes?" }\end{array}$ & Falling reactivity (IBQ, IBQ-R) \\
\hline
\end{tabular}

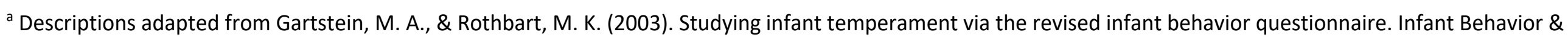

Development, 26(1), 64-86. 


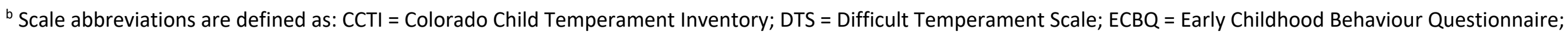

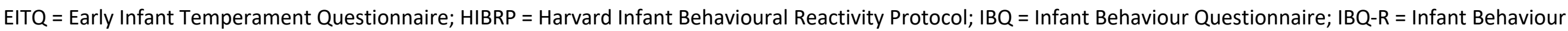

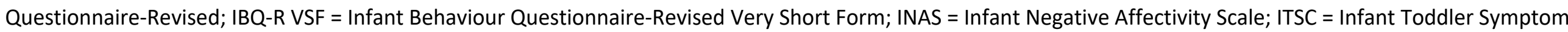

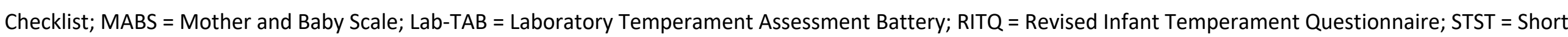
Temperament Scale for Toddler; TTS = Toddler Temperament Questionnaire. 


\section{Table 2. Characteristics of studies included}

\begin{tabular}{|c|c|c|c|c|c|c|c|c|c|c|c|}
\hline Study & Country & $\mathbf{N}$ & Exposure & $\begin{array}{l}\text { Exposure } \\
\text { measure }\end{array}$ & $\begin{array}{l}\text { Preconception } \\
\text { exposure }\end{array}$ & $\begin{array}{l}\text { Antenatal } \\
\text { exposure }^{\text {b }}\end{array}$ & $\begin{array}{l}\text { Postnatal } \\
\text { exposure }\end{array}$ & $\begin{array}{l}\text { Parent } \\
\text { assessed }\end{array}$ & Outcome & $\begin{array}{l}\text { Outcome } \\
\text { measure }^{\mathrm{cd}}\end{array}$ & $\begin{array}{l}\text { Infant } \\
\text { age at } \\
\text { follow- } \\
\text { up } \\
\text { (months) }\end{array}$ \\
\hline Alvik (2011) & Norway & 1303 & Anx; Dep & $\mathrm{H}-\mathrm{SCL}^{\mathrm{s}}$ & & T3 & & Mother & Negative affectivity & $\begin{array}{l}\text { DTS }^{p} ; I T S C^{p} ; \\
\text { SD }^{p}\end{array}$ & 6 \\
\hline $\begin{array}{l}\text { Baibazarova } \\
\text { (2013) }\end{array}$ & Netherlands & 158 & Anx & STAl $l^{\mathrm{s}}$ & & $\mathrm{T} 2$ & & Mother & $\begin{array}{l}\text { Frustration/irritability; } \\
\text { Fear }\end{array}$ & $\mathrm{IBQ}-\mathrm{R}^{\mathrm{p}}$ & 3 \\
\hline Bhat (2015) & India & 100 & Mixed & GHQ-28 & & $\mathrm{T} 3$ & & Mother & Negative affectivity & EITQ $^{p}$ & 1 \\
\hline $\begin{array}{l}\text { Braithwaite } \\
\text { (2015) }\end{array}$ & UK & $\begin{array}{l}40 \\
48\end{array}$ & Dep & EPDS $^{s}$ & & $\mathrm{~T} 2 ; \mathrm{T} 3$ & & Mother & Frustration/irritability & $\mathrm{IBQ}^{\mathrm{p}}$ & 2 \\
\hline $\begin{array}{l}\text { Chazan } \\
\text { (1998) }\end{array}$ & USA & 93 & Dep & CES-D ${ }^{S}$ & & ns & & Mother & Negative affectivity & $\mathrm{CCTI}$ & 4 \\
\hline $\begin{array}{l}\text { Coplan } \\
\text { (2005) }\end{array}$ & Canada & 46 & Anx & STAl $I^{s}$ & & T3 & & Mother & Frustration/irritability & $\mathrm{IBQ}^{\mathrm{p}}$ & 3 \\
\hline $\begin{array}{l}\text { Davis } \\
\text { (2004) }\end{array}$ & USA & 22 & Anx; Dep & STAI'; CES-D ${ }^{\mathrm{s}}$ & & T3 & 2 months & Mother & Negative affectivity & $\begin{array}{l}\text { HIBRP } \\
\text { protocol and } \\
\text { scoring }^{\circ}\end{array}$ & 4 \\
\hline $\begin{array}{l}\text { Davis } \\
\text { (2007) }\end{array}$ & USA & 247 & Anx; Dep & STAl'; CES-D ${ }^{\mathrm{s}}$ & & T2; T3 & & Mother & Fear & $\mathrm{IBQ}^{\mathrm{p}}$ & 2 \\
\hline $\begin{array}{l}\text { de Weerth } \\
\text { (2013) }\end{array}$ & Netherlands & $\begin{array}{l}105 ; \\
97 ; \\
95\end{array}$ & Anx & $\mathrm{STAl}^{\mathrm{s}} ; \mathrm{PRAQ}-\mathrm{R}^{\mathrm{s}}$ & & T3 & & Mother & Negative affectivity & $\begin{array}{l}\text { Study- } \\
\text { derived } \\
\text { maternal } \\
\text { separation } \\
\text { protocol } \\
\text { with study- } \\
\text { derived } \\
\text { scoring }^{\circ}\end{array}$ & 9 \\
\hline
\end{tabular}




\begin{tabular}{|c|c|c|c|c|c|c|c|c|c|c|c|}
\hline Study & Country & $\mathbf{N}$ & Exposure & $\begin{array}{l}\text { Exposure } \\
\text { measure }^{a}\end{array}$ & $\begin{array}{l}\text { Preconception } \\
\text { exposure }\end{array}$ & $\begin{array}{l}\text { Antenatal } \\
\text { exposure }^{b}\end{array}$ & $\begin{array}{l}\text { Postnatal } \\
\text { exposure }\end{array}$ & $\begin{array}{l}\text { Parent } \\
\text { assessed }\end{array}$ & Outcome & $\begin{array}{l}\text { Outcome } \\
\text { measure }^{c d}\end{array}$ & $\begin{array}{l}\text { Infant } \\
\text { age at } \\
\text { follow- } \\
\text { up } \\
\text { (months) }\end{array}$ \\
\hline $\begin{array}{l}\text { Della } \\
\text { Vedova } \\
(2014)\end{array}$ & Italy & 107 & Anx; Dep & STAI $^{s} ;$ CES-D ${ }^{S}$ & & T3 & & Mother & Negative affectivity & $\mathrm{EITQ}^{\mathrm{p}}$ & 3 \\
\hline $\begin{array}{l}\text { Edwards } \\
\text { (2017) }\end{array}$ & USA & 99 & Anx; Dep & $B D I-I^{s} ; B A I^{s}$ & & & 6 months & Mother & Negative affectivity & $I B Q-R^{p}$ & 8 \\
\hline $\begin{array}{l}\text { Erickson } \\
(2018)\end{array}$ & USA & 142 & Anx; Dep & $\begin{array}{l}\text { STAI }^{\text {s; }} \text { PRAQ-R } \\
\text { EPDS }^{s}\end{array}$ & & T3 & & Mother & Negative affectivity & $I B Q-R^{p}$ & 2 \\
\hline $\begin{array}{l}\text { Erickson } \\
\text { (2019) }\end{array}$ & Canada & $\begin{array}{l}185 \\
163\end{array}$ & Anx; Dep & $\begin{array}{l}\text { EPDS }^{s} ; \mathrm{HAMD}^{\mathrm{s}} ; \\
\mathrm{HAMA}^{\mathrm{s}}\end{array}$ & & T3 & 3 months & Mother & $\begin{array}{l}\text { Frustration/irritability; } \\
\text { Fear }\end{array}$ & $\mathrm{IBQ}^{\mathrm{p}}$ & $3 ; 6 ; 10$ \\
\hline $\begin{array}{l}\text { Fernandes } \\
(2018)\end{array}$ & India & 58 & Dep & EPDS $^{s}$ & & T3 & & Mother & $\begin{array}{l}\text { Negative affectivity; } \\
\text { Frustration/irritability }\end{array}$ & $\mathrm{IBQ}^{\mathrm{p}}$ & 2 \\
\hline $\begin{array}{l}\text { Forman } \\
(2007)\end{array}$ & USA & 136 & Dep & $\mathrm{SCID}^{\mathrm{d}} ; \mathrm{HAMD}^{\mathrm{s}}$ & & & 6 months & Mother & Negative affectivity & $\mathrm{IBQ}^{\mathrm{p}}$ & 9 \\
\hline Frost (1996) & USA & 476 & Anx; Dep & $\mathrm{STAl}^{\mathrm{s}} ; \mathrm{CES}-\mathrm{D}^{\mathrm{s}}$ & & $\mathrm{T} 2$ & & Father & Frustration/irritability & $\mathrm{IBQ}^{\mathrm{p}}$ & 1 \\
\hline $\begin{array}{l}\text { Gustafsson } \\
(2018)\end{array}$ & USA & 68 & Dep & CES-D ${ }^{S}$ & & $\mathrm{~T} 2$ & & Mother & $\begin{array}{l}\text { Negative affectivity; } \\
\text { Slow recovery from } \\
\text { distress; } \\
\text { Frustration/irritability; } \\
\text { Fear; Sadness }\end{array}$ & $\begin{array}{l}\text { IBQ- } \mathrm{R}^{\mathrm{p}} \text {; Still- } \\
\text { face and } \\
\text { arm- } \\
\text { restraint } \\
\text { protocols } \\
\text { with study- } \\
\text { derived } \\
\text { scoring }^{\circ}\end{array}$ & 6 \\
\hline $\begin{array}{l}\text { Henrichs } \\
\text { (2009) }\end{array}$ & Netherlands & 2997 & Anx & $\mathrm{BSI}^{\mathrm{s}} ; \mathrm{POQ}^{\mathrm{s}}$ & & $\mathrm{T} 1 ; \mathrm{T} 2$ & & Mother & $\begin{array}{l}\text { Frustration/irritability; } \\
\text { Fear; Slow recovery } \\
\text { from distress; Sadness }\end{array}$ & $I B Q-R^{p}$ & 6 \\
\hline
\end{tabular}




\begin{tabular}{|c|c|c|c|c|c|c|c|c|c|c|c|}
\hline Study & Country & $\mathbf{N}$ & Exposure & $\begin{array}{l}\text { Exposure } \\
\text { measure }^{a}\end{array}$ & $\begin{array}{l}\text { Preconception } \\
\text { exposure }\end{array}$ & $\begin{array}{l}\text { Antenatal } \\
\text { exposure }^{\text {b }}\end{array}$ & $\begin{array}{l}\text { Postnatal } \\
\text { exposure }\end{array}$ & $\begin{array}{l}\text { Parent } \\
\text { assessed }\end{array}$ & Outcome & $\begin{array}{l}\text { Outcome } \\
\text { measure }\end{array}$ & $\begin{array}{l}\text { Infant } \\
\text { age at } \\
\text { follow- } \\
\text { up } \\
\text { (months) }\end{array}$ \\
\hline $\begin{array}{l}\text { Isosavi } \\
(2017)^{d}\end{array}$ & Israel & 477 & Dep & EPDS $^{\mathrm{s}}$ & & $\mathrm{T} 2$ & & Mother & $\begin{array}{l}\text { Fear; } \\
\text { Frustration/irritability; } \\
\text { Sadness; Slow } \\
\text { recovery from distress }\end{array}$ & $\mathrm{IBQ}-\mathrm{R}^{\mathrm{p}}$ & 4 \\
\hline $\begin{array}{l}\text { Jonas } \\
\text { (2015) }\end{array}$ & Canada & 170 & Anx & STAl $I^{\mathrm{s}}$ & & & 3 months & Mother & Negative affectivity & $\mathrm{ECBQ}^{p}$ & 18 \\
\hline $\begin{array}{l}\text { Jover } \\
\text { (2014) }\end{array}$ & Spain & 317 & Anx; Dep & STAl $^{\text {s; }}$ EPDS $^{s}$ & & & 2 days & Mother & Frustration/irritability & $\mathrm{MABS}^{p}$ & 2 \\
\hline Kim (2020) & $\begin{array}{l}\text { New } \\
\text { Zealand }\end{array}$ & 5568 & Dep & $\mathrm{EPDS}^{\mathrm{s}}$ & & T3 & & Mother & $\begin{array}{l}\text { Negative affectivity; } \\
\text { Fear }\end{array}$ & IBQ-R VSF ${ }^{p}$ & 9 \\
\hline $\begin{array}{l}\text { Kukkonen } \\
\text { (2019) }\end{array}$ & Finland & 347 & Dep & EPDS $^{s}$ & & & $\begin{array}{l}3 \\
\text { months; } \\
6 \text { months }\end{array}$ & $\begin{array}{l}\text { Mother; } \\
\text { Father }\end{array}$ & Negative affectivity & $I B Q-R^{p}$ & $6 ; 12$ \\
\hline $\begin{array}{l}\text { Leerkes } \\
\text { (2003) }\end{array}$ & USA & 90 & Dep & CES-D ${ }^{S}$ & & T3 & 5 months & Mother & Frustration/irritability & $\begin{array}{l}\mathrm{IBQ}^{\mathrm{p}} \text {; Lab- } \\
\mathrm{TAB} \text { and arm } \\
\text { restraint } \\
\text { protocols } \\
\text { with INAS } \\
\text { scoring }^{\circ}\end{array}$ & $5 ; 6$ \\
\hline $\begin{array}{l}\text { Lemola } \\
\text { (2009) }\end{array}$ & Switzerland & $\begin{array}{l}374 ; \\
323\end{array}$ & Dep & $\mathrm{EPDS}^{\mathrm{s}}$ & & & $\begin{array}{l}1.5 \\
\text { months; } \\
5 \text { months }\end{array}$ & Mother & Frustration/irritability & $\mathrm{IBQ}^{\mathrm{p}}$ & $5 ; 17$ \\
\hline $\begin{array}{l}\text { Luecken } \\
\text { (2015) }\end{array}$ & USA & 312 & Dep & $\mathrm{EPDS}^{\mathrm{s}}$ & & $\mathrm{T} 1$ & & Mother & Negative affectivity & $I B Q-R^{p}$ & 1 \\
\hline $\begin{array}{l}\text { McLean } \\
\text { (2019) }\end{array}$ & Australia & 104 & Dep & $\mathrm{EPDS}^{\mathrm{s}}$ & & & 6 months & Mother & Negative affectivity & STST & 16 \\
\hline
\end{tabular}




\begin{tabular}{|c|c|c|c|c|c|c|c|c|c|c|c|}
\hline Study & Country & $\mathbf{N}$ & Exposure & $\begin{array}{l}\text { Exposure } \\
\text { measure }^{\text {a }}\end{array}$ & $\begin{array}{l}\text { Preconception } \\
\text { exposure }\end{array}$ & $\begin{array}{l}\text { Antenatal } \\
\text { exposure }^{\text {b }}\end{array}$ & $\begin{array}{l}\text { Postnatal } \\
\text { exposure }\end{array}$ & $\begin{array}{l}\text { Parent } \\
\text { assessed }\end{array}$ & Outcome & $\begin{array}{l}\text { Outcome } \\
\text { measure }^{\text {cd }}\end{array}$ & $\begin{array}{l}\text { Infant } \\
\text { age at } \\
\text { follow- } \\
\text { up } \\
\text { (months) }\end{array}$ \\
\hline $\begin{array}{l}\text { Metz } \\
\text { (2018) }\end{array}$ & Netherlands & $\begin{array}{l}135 \\
131 ; \\
130\end{array}$ & Anx & $\mathrm{ADIS}^{\mathrm{d}}$ & & ns & & $\begin{array}{l}\text { Mother; } \\
\text { Father }\end{array}$ & Fear & $I B Q-R^{p}$ & $4 ; 12$ \\
\hline $\begin{array}{l}\text { Moscardino } \\
(2006)\end{array}$ & Italy & 28 & Dep & $\mathrm{EPDS}^{\mathrm{s}} ; \mathrm{POMS}^{\mathrm{s}}$ & & & 2 months & Mother & Negative affectivity & $\begin{array}{l}\text { Routine } \\
\text { vaccination } \\
\text { with study } \\
\text { derived } \\
\text { scoring }^{\circ}\end{array}$ & 4.5 \\
\hline $\begin{array}{l}\text { Nolvi } \\
\text { (2016) }\end{array}$ & Finland & 282 & Anx; Dep & $\begin{array}{l}\text { SCL-90'; PRAQ- } \\
\text { R2 }^{\text {s }} \text { EPDS }^{\text {s }}\end{array}$ & & $\mathrm{T} 1 ; \mathrm{T} 2 ; \mathrm{T} 3$ & & Mother & $\begin{array}{l}\text { Negative affectivity; } \\
\text { Fear; Sadness; Slow } \\
\text { recovery from } \\
\text { distress; } \\
\text { Frustration/irritability }\end{array}$ & $\mathrm{IBQ}-\mathrm{R}^{\mathrm{p}}$ & 6 \\
\hline $\begin{array}{l}\text { Nomura } \\
\text { (2014) }\end{array}$ & USA & 141 & Dep & $\mathrm{SCID}^{\mathrm{d}}$ & & ns & & Mother & $\begin{array}{l}\text { Fear; Sadness; Slow } \\
\text { recovery from } \\
\text { distress; } \\
\text { Frustration/irritability }\end{array}$ & $\mathrm{IBQ}-\mathrm{R}^{\mathrm{p}}$ & 6 \\
\hline $\begin{array}{l}\text { Nomura } \\
\text { (2019) }\end{array}$ & USA & 310 & Dep & $\mathrm{EPDS}^{\mathrm{S}}$ & & $\mathrm{T} 2$ & & Mother & $\begin{array}{l}\text { Frustration/irritability; } \\
\text { Fear; Slow recovery } \\
\text { from distress; Sadness }\end{array}$ & $\mathrm{IBQ}-\mathrm{R}^{\mathrm{p}}$ & 6 \\
\hline $\begin{array}{l}\text { Peltola } \\
\text { (2017) }\end{array}$ & Finland & 173 & Anx & STAI $I^{\mathrm{s}}$ & & T3 & & Mother & Negative affectivity & $I B Q-R^{p}$ & 8 \\
\hline $\begin{array}{l}\text { Pluess } \\
\text { (2011) }\end{array}$ & Netherlands & 1513 & Anx & $B S I^{\mathrm{s}}$ & & $\mathrm{T} 2$ & & Mother & Negative affectivity & $I B Q-R^{p}$ & 6 \\
\hline $\begin{array}{l}\text { Potapova } \\
\text { (2014) }\end{array}$ & USA & 98 & Anx; Dep & $\mathrm{BDI}-\mathrm{II}^{\mathrm{s}} ; \mathrm{BA} \mathrm{I}^{\mathrm{s}}$ & & & 4 months & Father & Negative affectivity & $\mathrm{IBQ}-\mathrm{R}^{\mathrm{p}}$ & 6 \\
\hline
\end{tabular}




\begin{tabular}{|c|c|c|c|c|c|c|c|c|c|c|c|}
\hline Study & Country & $\mathbf{N}$ & Exposure & $\begin{array}{l}\text { Exposure } \\
\text { measure }^{\mathrm{a}}\end{array}$ & $\begin{array}{l}\text { Preconception } \\
\text { exposure }\end{array}$ & $\begin{array}{l}\text { Antenatal } \\
\text { exposure }^{\text {b }}\end{array}$ & $\begin{array}{l}\text { Postnatal } \\
\text { exposure }\end{array}$ & $\begin{array}{l}\text { Parent } \\
\text { assessed }\end{array}$ & Outcome & $\begin{array}{l}\text { Outcome } \\
\text { measure }\end{array}$ & $\begin{array}{l}\text { Infant } \\
\text { age at } \\
\text { follow- } \\
\text { up } \\
\text { (months) }\end{array}$ \\
\hline $\begin{array}{l}\text { Prino } \\
\text { (2016) }\end{array}$ & Italy & 58 & Anx; Dep & STAII $^{\text {s }}$ EPDS $^{s}$ & & $\mathrm{~T} 2$ & & $\begin{array}{l}\text { Mother; } \\
\text { Father }\end{array}$ & $\begin{array}{l}\text { Frustration/irritability; } \\
\text { Fear; Slow recovery } \\
\text { from distress; Sadness }\end{array}$ & $I B Q-R^{p}$ & 3 \\
\hline $\begin{array}{l}\text { Rouse } \\
\text { (2014) }\end{array}$ & USA & 77 & Anx; Dep & $\begin{array}{l}\text { STAI }^{\text {s }} \text { SCID }^{d} \\
\text { BDI-II }^{s}\end{array}$ & & $\mathrm{~T} 1 ; \mathrm{T} 2 ; \mathrm{T} 3$ & & Mother & $\begin{array}{l}\text { Negative affectivity; } \\
\text { Fear; Slow recovery } \\
\text { from distress; } \\
\text { Sadness; } \\
\text { Frustration/irritability }\end{array}$ & $I B Q-R^{p}$ & 3 \\
\hline $\begin{array}{l}\text { Sharp } \\
(2012)\end{array}$ & UK & 271 & Dep & EPDS $^{S}$ & & T3 & & Mother & $\begin{array}{l}\text { Frustration/irritability; } \\
\text { Fear }\end{array}$ & $\mathrm{IBQ}-\mathrm{R}^{\mathrm{p}}$ & 6 \\
\hline Spry (2019) & Australia & 1231 & Anx; Dep & $\begin{array}{l}\text { EPDS }^{\mathrm{s}} ; \mathrm{CIS}^{\mathrm{d}} \text {; } \\
\text { GHQ-12; } \\
\text { SMFQ; } \\
\text { SBPC- } \\
\text { SF }^{\mathrm{s}} \text { RCMAS } \\
\text { DASS- } 21^{\mathrm{s}}\end{array}$ & $\begin{array}{l}\text { Adolescent; } \\
\text { young adult }\end{array}$ & T3 & & Mother & Negative affectivity & $\mathrm{STST}^{\mathrm{p}}$ & 12 \\
\hline $\begin{array}{l}\text { Sugawara } \\
\text { (1999) }\end{array}$ & Japan & 817 & Dep & $\mathrm{SDS}^{\mathrm{s}}$ & & & $\begin{array}{l}5 \text { days; } \\
12 \\
\text { months }\end{array}$ & Mother & $\begin{array}{l}\text { Fear; } \\
\text { Frustration/irritability }\end{array}$ & $\mathrm{RITQ}^{\mathrm{p}} ; \mathrm{TTS}^{\mathrm{p}}$ & $6 ; 18$ \\
\hline $\begin{array}{l}\text { Thomas } \\
\text { (2017) }\end{array}$ & Canada & 254 & Anx; Dep & $\mathrm{PAS}^{\mathrm{s}} ; \mathrm{EPDS}^{\mathrm{s}}$ & & T2; T3 & & Mother & Negative affectivity & $I B Q-R^{p}$ & 3 \\
\hline Ting (2012) & China & 121 & Anx; Dep & HADS $^{\text {s. }}$ EPDS $^{s}$ & & & $\begin{array}{l}1.5 \\
\text { months }\end{array}$ & Father & $\begin{array}{l}\text { Frustration/irritability; } \\
\text { Fear; Sadness; Slow } \\
\text { recovery from distress }\end{array}$ & $\mathrm{IBQ}-\mathrm{R}^{\mathrm{p}}$ & 6 \\
\hline $\begin{array}{l}\text { van den } \\
\text { Heuvel } \\
(2015)\end{array}$ & Netherlands & 90 & Anx & SCL-90 ${ }^{\mathrm{S}}$ & & $\mathrm{T} 2$ & & Mother & Negative affectivity & $\mathrm{IBQ}-\mathrm{R}^{\mathrm{p}}$ & 10 \\
\hline
\end{tabular}




\begin{tabular}{|c|c|c|c|c|c|c|c|c|c|c|c|}
\hline Study & Country & $\mathbf{N}$ & Exposure & $\begin{array}{l}\text { Exposure } \\
\text { measure }^{a}\end{array}$ & $\begin{array}{l}\text { Preconception } \\
\text { exposure }\end{array}$ & $\begin{array}{l}\text { Antenatal } \\
\text { exposure }^{\text {b }}\end{array}$ & $\begin{array}{l}\text { Postnatal } \\
\text { exposure }\end{array}$ & $\begin{array}{l}\text { Parent } \\
\text { assessed }\end{array}$ & Outcome & $\begin{array}{l}\text { Outcome } \\
\text { measure }\end{array}$ & $\begin{array}{l}\text { Infant } \\
\text { age at } \\
\text { follow- } \\
\text { up } \\
\text { (months) }\end{array}$ \\
\hline $\begin{array}{l}\text { Werner } \\
\text { (2007) }\end{array}$ & USA & 50 & Anx; Dep & $\mathrm{SCID}^{\mathrm{d}}$ & & $\mathrm{T} 2$ & & Mother & Negative affectivity & $\mathrm{IBQ}^{\mathrm{p}} ; \mathrm{HIBRP}^{\circ}$ & 4 \\
\hline $\begin{array}{l}\text { Zhang } \\
\text { (2017) }\end{array}$ & USA & 153 & Dep & $\mathrm{EPDS}^{\mathrm{s}}$ & & $\mathrm{T} 2$ & & Mother & Negative affectivity & $I B Q-R^{p}$ & 6 \\
\hline
\end{tabular}

${ }^{\mathrm{a}} \mathrm{s}=$ symptom checklist; $\mathrm{d}=$ diagnostic interview

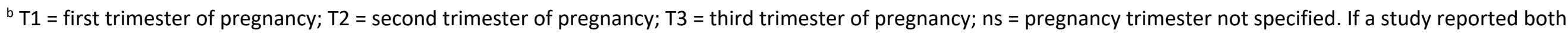
trimester-specific estimates and mean pregnancy estimates, we only included trimester-specific estimates.

${ }^{c} p=$ parent-report; $o=$ observation

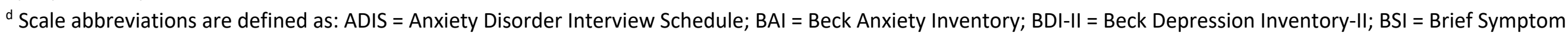

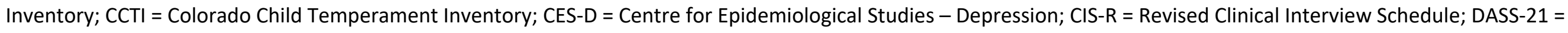

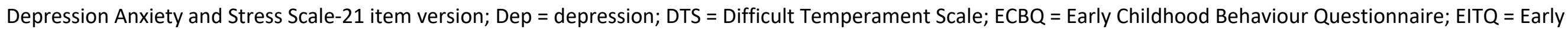

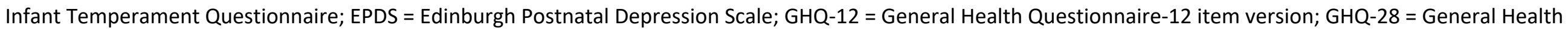

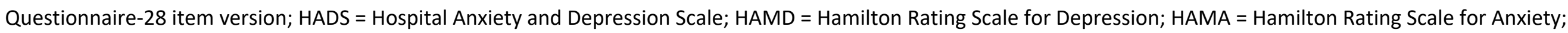

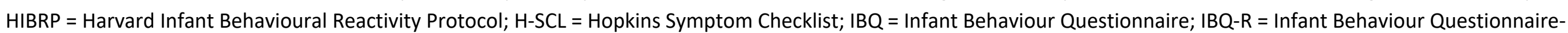

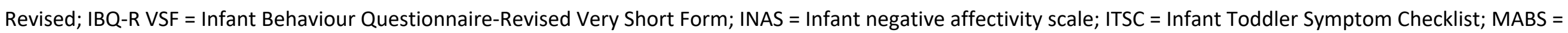

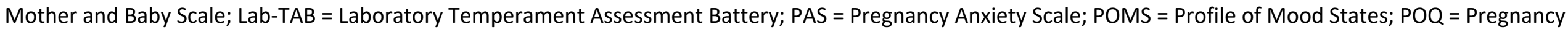

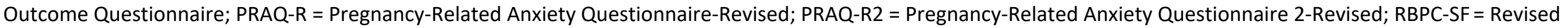

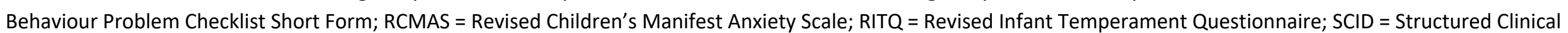

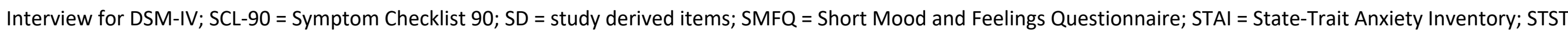
= Short Temperament Scale for Toddlers; TTS = Toddler Temperament Questionnaire. 
Table 3. Results of moderator analyses for the association between maternal internalizing symptoms and infant negative affectivity

\begin{tabular}{|c|c|c|c|c|c|c|c|c|}
\hline \multirow{2}{*}{ Overall association } & \multirow{2}{*}{$\begin{array}{l}k \\
42\end{array}$} & \multirow{2}{*}{$\begin{array}{l}n \\
149\end{array}$} & \multirow{2}{*}{$\begin{array}{c}r \\
0.17\end{array}$} & \multicolumn{2}{|c|}{$95 \% \mathrm{Cl}$} & \multirow{2}{*}{$\begin{array}{c}1^{2} \\
80.76\end{array}$} & \multirow{2}{*}{$\begin{array}{c}\boldsymbol{p} \\
<0.001\end{array}$} & \multirow{2}{*}{$\begin{array}{c}\text { model } p \\
-\end{array}$} \\
\hline & & & & $(0.14$ & $0.21)$ & & & \\
\hline \multicolumn{9}{|l|}{ Results of moderator analyses } \\
\hline \multicolumn{9}{|c|}{ Exposure and outcome constructs assessed } \\
\hline Infant negative affectivity ${ }^{a}$ & 42 & 193 & & & & & & 0.044 \\
\hline General negative affectivity & 26 & 62 & 0.21 & $(0.17$ & $0.26)$ & 85.13 & $<0.001$ & \\
\hline Sadness & 8 & 21 & 0.22 & $(0.06$ & $0.37)$ & 87.05 & 0.015 & \\
\hline Fear & 15 & 39 & 0.12 & $(0.07$ & $0.16)$ & 81.21 & $<0.001$ & \\
\hline Frustration/irritability & 18 & 50 & 0.14 & $(0.08$ & $0.20)$ & 72.22 & $<0.001$ & \\
\hline Slow recovery from distress & 8 & 21 & 0.14 & $(0.03$ & $0.24)$ & 74.54 & 0.021 & \\
\hline Maternal internalizing symptoms ${ }^{b}$ & 38 & 135 & & & & & & 0.571 \\
\hline Depression & 29 & 76 & 0.17 & $(0.12$ & $0.21)$ & 84.53 & $<0.001$ & \\
\hline Anxiety & 19 & 59 & 0.19 & $(0.15$ & $0.23)$ & 52.06 & $<0.001$ & \\
\hline \multicolumn{9}{|l|}{ Timing of assessment } \\
\hline Infant negative affectivity & 42 & 149 & & & & & & 0.865 \\
\hline$<6$ months & 22 & 75 & 0.16 & $(0.11$ & $0.21)$ & 52.25 & $<0.001$ & \\
\hline$\geq 6$ months & 24 & 74 & 0.17 & $(0.12$ & $0.22)$ & 87.03 & $<0.001$ & \\
\hline Maternal internalizing symptoms & 42 & 149 & & & & & & 0.081 \\
\hline Preconception ${ }^{c}$ & 1 & 3 & - & - & - & - & - & \\
\hline Antenatal ${ }^{d}$ & 33 & 116 & 0.18 & $(0.13$ & $0.22)$ & 84.46 & $<0.001$ & 0.797 \\
\hline Trimester 1 & 2 & 5 & 0.15 & $(-0.06$ & $0.35)$ & 48.42 & 0.069 & \\
\hline Trimester 2 & 15 & 59 & 0.18 & (0.11 & $0.25)$ & 74.15 & $<0.001$ & \\
\hline Trimester 3 & 20 & 44 & 0.18 & $(0.12$ & $0.23)$ & 87.23 & $<0.001$ & \\
\hline Postnatal & 12 & 30 & 0.17 & $(0.10$ & $0.23)$ & 53.75 & $<0.001$ & 0.307 \\
\hline$<6$ months & 9 & 24 & 0.14 & $(0.06$ & $0.22)$ & 55.55 & 0.005 & \\
\hline$\geq 6$ months & 5 & 6 & 0.19 & $(0.08$ & $0.31)$ & 44.13 & 0.012 & \\
\hline \multicolumn{9}{|l|}{ Assessment mode } \\
\hline Infant negative affectivity & 42 & 149 & & & & & & 0.674 \\
\hline Observer-rated & 6 & 19 & 0.16 & $(-0.08$ & $0.38)$ & 67.94 & 0.145 & \\
\hline Parent-report & 38 & 130 & 0.18 & $(0.15$ & $0.22)$ & 81.83 & $<0.001$ & \\
\hline Maternal internalizing symptoms & 42 & 149 & & & & & & 0.628 \\
\hline Self-report & 38 & 135 & 0.18 & $(0.14$ & $0.22)$ & 83.28 & $<0.001$ & \\
\hline Clinical interview & 6 & 14 & 0.19 & $(0.09$ & $0.30)$ & 81.69 & 0.006 & \\
\hline Publication status & 42 & 149 & & & & & & 0.076 \\
\hline Published study & 38 & 140 & 0.17 & $(0.13$ & $0.21)$ & 82.11 & $<0.001$ & \\
\hline Unpublished study & 4 & 9 & 0.22 & $(0.15$ & $0.29)$ & 0.00 & 0.006 & \\
\hline \multicolumn{9}{|c|}{ Note: $\mathrm{k}=$ number of studies; $\mathrm{n}=$ number of estimates; $\mathrm{r}=$ Pearson correlation coefficient; $\mathrm{I}^{2}=$ proportion of observed variance not } \\
\hline \multicolumn{9}{|c|}{ a The meta-regression and moderation analyses for outcome construct assessed was examined using all estimates from all studies. } \\
\hline \multicolumn{9}{|c|}{$\begin{array}{l}\text { The remainder of the analyses excluded estimates for the facet dimensions if estimates for the global negative affectivity } \\
\text { construct were also provided, to avoid double-counting data points. }\end{array}$} \\
\hline
\end{tabular}


${ }^{c}$ Empty rows indicate too few studies in the specified category $(k<2)$ for inclusion in meta-regression or moderator analyses.

${ }^{\mathrm{d}}$ Studies were excluded from the meta-regression and moderation analysis for exposure timing by pregnancy trimester if pregnancy trimester was unknown. 
Table 4. Results of moderator analyses for the association between paternal internalizing symptoms and infant negative affectivity

\begin{tabular}{|c|c|c|c|c|c|c|c|c|}
\hline & k & $\mathbf{n}$ & $r$ & \multicolumn{2}{|c|}{$95 \% \mathrm{Cl}$} & $1^{2}$ & $p$ & model $p$ \\
\hline Overall association & 6 & 40 & 0.13 & $(0.04$ & $0.22)$ & 60.69 & 0.014 & - \\
\hline \multicolumn{9}{|l|}{ Results of moderator analyses } \\
\hline \multicolumn{9}{|c|}{ Exposure and outcome constructs assessed } \\
\hline Infant negative affectivity & 6 & 40 & & & & & & $0.003^{a}$ \\
\hline General negative affectivity & 2 & 4 & 0.20 & $(-0.19$ & $0.53)$ & 0.00 & 0.099 & \\
\hline Sadness & 2 & 8 & 0.20 & $(0.18$ & $0.22)$ & 89.00 & 0.005 & \\
\hline Fear & 3 & 10 & 0.03 & $(-0.05$ & $0.11)$ & 3.10 & 0.210 & \\
\hline Frustration/irritability & 3 & 10 & 0.13 & $(-0.11$ & $0.35)$ & 72.40 & 0.139 & \\
\hline Slow recovery from distress & 2 & 8 & 0.21 & $(0.08$ & $0.35)$ & 59.78 & 0.033 & \\
\hline Paternal internalizing symptoms ${ }^{b}$ & 5 & 39 & & & & & & 0.329 \\
\hline Anxiety & 4 & 23 & 0.10 & $(-0.05$ & $0.24)$ & 71.12 & 0.128 & \\
\hline Depression & 4 & 16 & 0.12 & $(0.01$ & $0.23)$ & 50.27 & 0.039 & \\
\hline \multicolumn{9}{|l|}{ Timing of assessment } \\
\hline Infant negative affectivity & 6 & 40 & & & & & & 0.138 \\
\hline$<6$ months & 3 & 27 & 0.09 & $(-0.04$ & $0.21)$ & 65.23 & 0.096 & \\
\hline$\geq 6$ months & 4 & 13 & 0.15 & $(0.01$ & $0.29)$ & 35.62 & 0.041 & \\
\hline Paternal internalizing symptoms & 6 & 40 & & & & & & 0.022 \\
\hline Antenatal & 3 & 28 & 0.07 & $(-0.04$ & $0.19)$ & 65.30 & 0.109 & - \\
\hline Postnatal & 3 & 12 & 0.19 & $(0.09$ & $0.28)$ & 0.00 & 0.018 & \\
\hline Publication status & 6 & 40 & & & & & & 0.781 \\
\hline Published study & 3 & 27 & 0.15 & $(-0.12$ & $0.40)$ & 71.85 & 0.140 & \\
\hline Unpublished study & 3 & 13 & 0.12 & $(-0.10$ & $0.33)$ & 60.76 & 0.133 & \\
\hline \multicolumn{9}{|c|}{$\begin{array}{l}\text { Note: } \mathrm{k}=\text { number of studies; } \mathrm{n}=\text { number of estimates; } \mathrm{r}=\text { Pearson correlation coefficient; } \mathrm{l}^{2}=\text { proportion of observed } \mathrm{v} \\
\text { attributable to sampling error; } p=p \text { value for the Pearson correlation coefficient of exposure-outcome associations wi } \\
\text { specified subgroup; model } p=p \text { value for the test of effect size differences between levels of the moderator variable. } \\
\text { a Using Eigen-decomposition } \mathrm{F}(\mathrm{EDF}) \text { test for small sample correction. }\end{array}$} \\
\hline
\end{tabular}


Figure 1. Prisma flow diagram reporting study selection process.
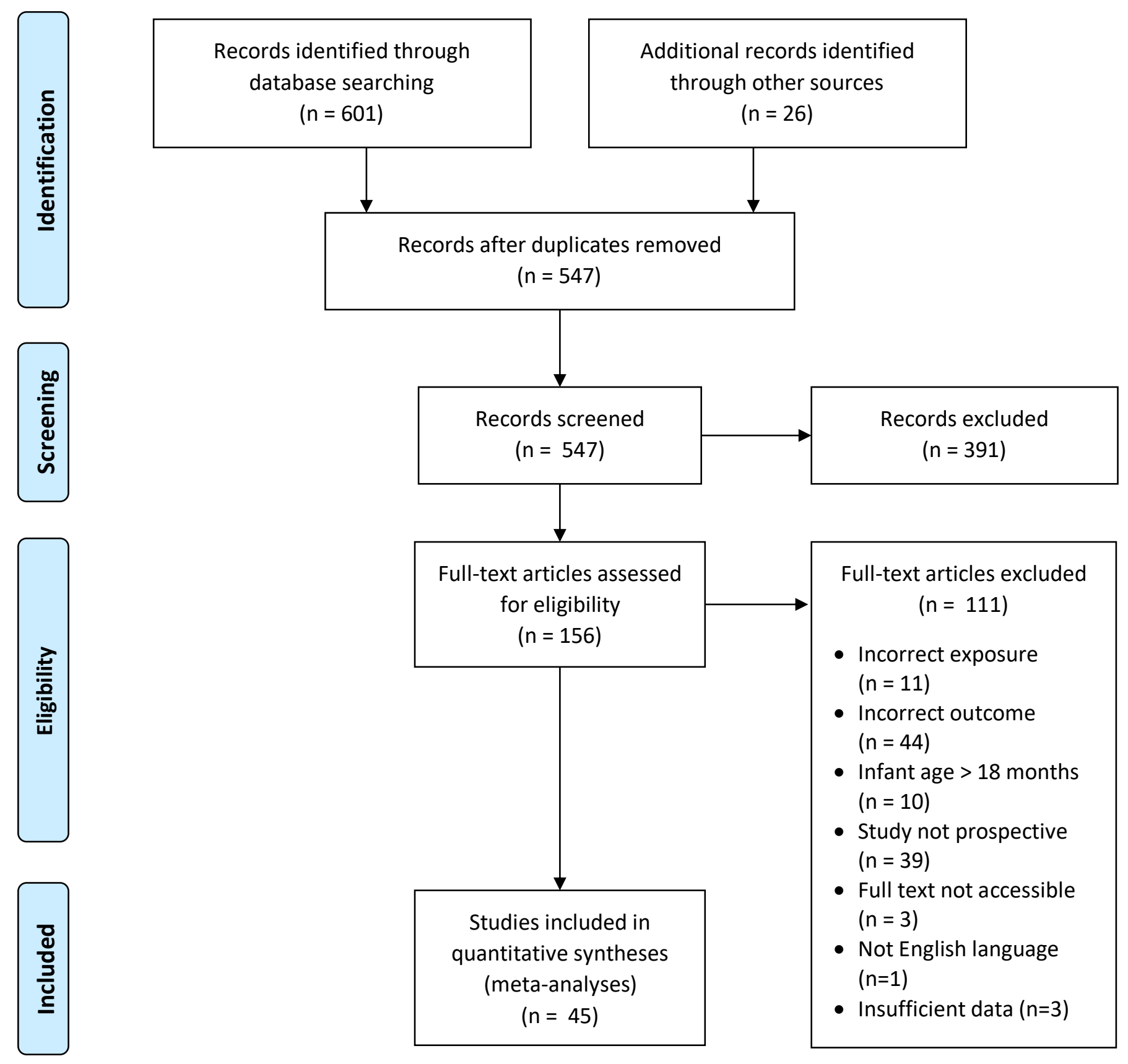